\title{
Çine-Tepecik'in Kültürel Gelişiminde Kentleşme Sürecini Anlamak
}

\section{Understanding the Urbanization Process in Çine-Tepecik's Cultural Development}

\author{
Sevinç Günel ${ }^{1}$ (])
}

1Hacettepe Üniversitesi, Edebiyat Fakültesi, Arkeoloji Bölümü, Ankara, Türkiye

\section{ORCID ID: S.G. 0000-0001-9455-5135}

Sorumlu yazar/Corresponding author: Sevinç Günel (Prof. Dr.),

Hacettepe Üniversitesi, Edebiyat Fakültesi, Arkeoloji Bölümü, Ankara, Türkiye E-posta: sgunel@hacettepe.edu.tr; sevincgunel@gmail.com

Başvuru/Submitted: 31.05 .2021 Revizyon Talebi/Revision Requested: 22.07.2021

Son Revizyon/Last Revision Received: 29.07.2021

Kabul/Accepted: 29.07 .2021

Atıf/Citation: Gunel, S. (2021). Çine-Tepecik'in kültürel gelişiminde kentleșme sürecini anlamak. Anadolu Araștirmalarl-Anatolian Research, 24, 117-144.

https://doi.org/10.26650/anar.2021.24.945531

\section{öz}

Çine-Tepecik Büyük Menderes'in güneyinde Çine ovasındaki konumuyla, bölgenin erken dönem kültür tarihine ışık tutan bir merkezdir. Tepecik'in en erken kültür kalıntıları, Kalkolitik döneme (Ege kronolojisinde Geç Neolitik) tarihlenmekte ve yerleşim süreci, Geç Tunç Çağı sonuna değin takip edilmektedir. Bu kronolojik gelişimde, seramik geleneği, tasvir sanatı ve alet teknolojisi, Tepecik'te yaşayan toplumların sosyal yaşamının belirlenmesinde öne çıkan kanıtlardır. Arkeolojik veriler, Batı Anadolu ve Ege dünyasıyla bağlantılı bir kültürel ve kronolojik gelişimi göstermiştir. Tepecik'in bölgelerarası iletişimindeki bu yakınlığı ve kültürel hareketliliği, Kalkolitik dönemden itibaren kapların bezeme stilinde, figürinlerde ve hammadde kaynaklarında görmek mümkündür. Hammadde kaynakları arasında obsidiyen ve çakmaktaşı Kalkolitik, Erken, Orta ve Geç Tunç Çağı́nda kullanım görmüştür. Obsidiyen, Ege adaları ve Orta Anadolu'dan temin edilmiş olup, en erken bölgelerarası ticari ilişkilere ışık tutmaktadır. Erken Tunç Çağı'nda, yerleşime ait mimari ve ölü gömme geleneklerinin anlaşılmasını sağlayan mezarlar, belli bir sosyo-kültürel düzeye ulaşmış toplumlara ait kanıtları vermektedir. Höyüğün stratigrafik ayrımına göre, MÖ 2. Binyılında savunma sistemine sahip yerleşim modeli, bir taraftan Çine-Tepecik'i bulunduğu coğrafyada güçlü bir kent olarak öne çıkarmakta diğer taraftan ise, Anadolu, Ege ve Doğu Akdeniz'e değin takip edilen kültürel ve ticari faaliyetlerin aktif olduğunu göstermektedir. Bu iletişimi, Orta ve Geç Tunç Çağı́nda, tasvir sanatına ait eserler, Miken boya bezeli kaplar, metal eserler ve filolojik anlamda mühür baskıları yansıtmaktadır. Özellikle Geç Tunç Çağı yerleşmesinde Miken seramik geleneği, Ege dünyasıyla olan kültürel birlikteliğini zengin bir buluntu grubuyla göstermektedir. Öte yandan Hitit Imparatorluk dönemine ait Anadolu hiyeroglif yazılı mühür baskıları ise, Tepecik'in Hititlerle iletişimini resmi boyutlara taşımaktadır. Arkeolojik ve filolojik veriler ışığında ÇineTepecik, Batı Anadolu'nun tarihi coğrafyasında Arzawa/Mira ülkesinin güneyinde, doğal yollara hakim, güçlü bir merkez konumuyla bölge arkeolojisine katkı sağlamaktadır.

Anahtar Kelimeler: Batı Anadolu, Çine-Tepecik, yerleşim süreci, sosyo-kültürel yaşam, bölgelerarası iletişim

\section{ABSTRACT}

With its location on the Çine plain south of the Greater Meander (Büyük Menderes), Çine-Tepecik is a settlement that sheds light on the region's early cultural history. 
Its earliest cultural remains date to the Chalcolithic Period (Late Neolithic in the Aegean chronology), and the settlement process extends to the end of the Late Bronze Age. In this chronological development, the pottery tradition, the art of depiction, and chipped stone technology are prominent lines of evidence characterizing Tepecik's social life. Archaeological data show cultural and chronological development associated with Western Anatolia and the Aegean world. This interregional communication and cultural dynamism can be followed through vessels' decoration style, cult items, and raw material sources since the Chalcolithic Period. Among raw materials sources, obsidian and flint were used in Chalcolithic, Early, Middle, and Late Bronze Periods. Obsidian in Tepecik was obtained from the Aegean islands and Central Anatolia, thus shedding light on the earliest interregional trade relations. Architectural remains of the settlement and its graves, which provide understanding of the Early Bronze Age's burial tradition, evidence a society that has reached a certain sociocultural level. According to the mound's stratigraphy, the settlement model with a defense system in the $2^{\text {nd }}$ millennium BC, on the one hand, highlights Çine-Tepecik as a strong city in its region, but on the other hand, shows that cultural and commercial activities with Anatolia, the Aegean, and the Eastern Mediterranean are active. This communication reflects the art of figurative depictions, Mycenaean painted vessels, metal artifacts, and philological evidence from seal impressions in the Middle and Late Bronze Ages. In the Late Bronze Age settlement, the Mycenaean painted pottery tradition, with a rich group of finds, demonstrates that Tepecik played an important role in the Aegean region's cultural network. In contrast, seal impressions with Anatolian hieroglyphs belonging to the Hittite Empire Period carry communication of the Tepecik settlement with the Hittites to official dimensions. In light of archaeological data and philological evidence, ÇineTepecik contributes to the region's archaeology with its strong position dominating natural roads in the south of Arzawa/Mira Land in Western Anatolia's historical geography.

Keywords: Western Anatolia, Çine-Tepecik, settlement process, sociocultural life, interregional communication

\section{EXTENDED ABSTRACT}

From early periods, Aegean geography, both at sea and on land, has naturally played an important role in site distribution and in cultural interaction among societies. In the Meander (Menderes) region in Western Anatolia, the Great Meander River (Büyük Menderes Nehri) and its tributaries to the south are important natural connections between the Aegean world and Central Anatolia. South of the Menderes, Çine-Tepecik provides understanding of this region's prehistoric and protohistoric cultures.

The Tepecik site reflects a long settlement process beginning in the Chalcolithic Period (in the Aegean chronology, Late Neolithic) until the end of the Bronze Age. The mound's latest settlement dates to the Carian-Geometric Period. In this stratigraphical definition, ÇineTepecik's life and cultural development continued uninterruptedly. During the site's early period (ca. 5463-5452 BC), the social structure of the settlement developed around agriculture and animal husbandry, as evidenced by buildings with storage facilities, the pottery tradition, chipped stone artifacts as blades, and bladelets and arrowheads of obsidian and flint. Lithic artifacts are the most widely used tools related with social life. Advanced technology has been applied to tools they used on animal species such as sheep, goats, deer, and cattle. The inhabitants grazed and hunted these animals while also farming grains. Obsidian's presence - of Central Anatolian and Aegean origin - also points to a wide-ranging, active interregional exchange network contributing to Tepecik's economic activities. This continuity of interregional contacts extends from the Chalcolithic to the end of the Bronze Age.

In addition to tool technology, decorated vessels and figurines shed light on the Chalcolithic community's sociocultural life. From the beginning of the Early Bronze Age, 
a developing social organization is evidenced on the mound by extensive building and the burial tradition. Finds from this period's burials, including pithos and jars, shed light on the community's differentiation of social status. In the Middle Bronze Age, foundations built of small stones and mudbricks reflect the settlement's architectural remains. Elaboration of the art of depiction is particularly striking among a major group of this period's artifacts. Among these finds are a deer-headed rhyton, a pithos of an anthropomorphic vessel, a terracotta model with stylized bulls (bucranium), and also a terracotta model with bull's horns. Among pottery finds, bowls and cups reflect the local pottery tradition of Western Anatolia. Conical cups, reminiscent of Minoan vessel forms, provide a parallel chronology. Cult items, which shed light on understanding of religion, echo the sociocultural structure. In addition to this period's rich finds, obsidian and rock crystal vessels had special meaning as prestige products. Settlement of the Middle Bronze Age shows impacts of a thick ash layer. Indeed, the southern part of the settlement is covered by a thick layer of volcanic ash over a large area, which has been scientifically confirmed to result from the eruption of Santorini.

In the Late Bronze Age, Tepecik possessed a fortification wall supported by towers. The architectural remains from this settlement phase revealed storage facilities and workshops, indicating a well-developed socioeconomic system. Agricultural products in the buildings were stored in pithoi. In the official storage building in this settlement, seal impressions with Anatolian hieroglyphs among storage vessels and pithoi indicate an economic organization based on local administrative power. Seal impressions date to the Hittite Empire $\left(13^{\text {th }}\right.$ century BC). Philological evidence from seal impressions and archaeological data from seal impressions' context clearly demonstrate official relations between the Hittite Empire and Tepecik's local administration. These finds are important not only for the Maeander region's historical geography but also for documenting the Hittite's impact on Western Anatolia. Meanwhile, Çine-Tepecik of the Late Bronze Age possessed cultural traits influenced by the Mycenean. Mycenean painted deep bowls, kylix, figurative kraters, and stirrup jars demonstrate that Tepecik played an important role in the Aegean region's exchange networks. The decoration of the Mycenean jars show typical Mycenaean motifs often found on various vessel types from the LH III B and III C in the Aegean. With its location at the crossroads, Çine-Tepecik was clearly a site active in interregional communications among the Aegean world, Central Anatolia, and the Eastern Mediterranean. 


\section{Giriş}

Bölgelerin coğrafi konumları ve iletişime olanak sağlayan doğal bağlantıları, yerleşmelerin sosyo-kültürel yapısını belirleyen faktörler arasındadır. Ege Denizi’nin kara ve adalar üzerindeki rolünü, yerleşik yaşamla birlikte bölgelerarası iletişimin sağlanmasından ve kültürel birlikteliğin oluşmasından takip etmek mümkündür. Batı Anadolu'nun dağlık arazi yapısı, nehir uzantılarının oluşturduğu ovalık alanları ve denize açılan kıyı şeridi, Ege'nin kültürel yapısında belirleyici olmuştur. Batı Anadolu, kültürel ve ticari faaliyetlerini bölgelerarası etkin kılan ve kentleşme sürecini yansıtan merkezleriyle dikkati çekmektedir. Bölgede, öncelikle hammadde kaynaklı değiş-tokuş sistemine dayalı ticaret, kronolojik gelişim içinde Ege, Anadolu ve Doğu Akdeniz’e uzanan bir ticaret sisteminin uygulandığ ve belli kentlerin öne çıktığı tarihi coğrafyayı yansıtmaktadır. Aydın İli’nde, doğu-batı doğrultusunda uzanan Aydın Dağı (Messogis) ve güneyinde Büyük Menderes (Meander) Nehri ve yan kolları, yerleşmelerin yayılım alanında uygun koşulları sağlamasının yanı sıra kültürel etkileşimlere açık bir bölgedir. Menderes’in güneyinde, yüksek dağ sıraları arasında Çine Çayı'nın (Marsyas) uzandığı ovada yer alan Çine-Tepecik, bölgenin Prehistorik ve Protohistorik dönemlerine ait yerel kültürüne ve çevre kültürlerle etkileşimine 1ş1k tutan bir höyüktür (Res. 1-2). Yerleşime ait kültür kalıntıları, Orta ve Geç Kalkolitik dönemden Geç Tunç Çağı sonuna uzanan bir yerleşim sürecini göstermektedir. ${ }^{1}$ Bu kronolojik gelişim, farklı kültür tabakalarına ait radyokarbon tarihlendirmelerine göre, MÖ 5463-5452 ile MÖ 12681157/1020 tarihlerini kapsayan bir zaman aralığını vermiştir. ${ }^{2}$

\section{Çine-Tepecik'in Yerleşim Sürecinde Yaşam ve Kültürel Olgular}

Çine-Tepecik’te yaşayan toplumların başlangıçta Ege ve Orta Anadolu bölgeleriyle hammadde kaynaklarına dayalı ticari faaliyetleri ekonomik açıdan öne çıkmıştır. Özellikle Orta ve Geç Tunç Çağı'nda, Ege, Orta Anadolu ve Doğu Akdeniz’e uzanan coğrafyada hammaddenin yanı sıra seramik, metal ve kült eşyalarıyla sosyo-kültürel iletişime etki etmiştir. Orta Kalkolitik dönemden itibaren Geç Tunç Çağı sonuna değin yerleşmenin her döneminde endüstriyel faaliyetler arasında yontmataş endüstrisi önemini yitirmeyen bir zanaat olarak görülmektedir. Yontmataş endüstrisinde, obsidiyen ve çakmaktaşının en yoğun işlenen hammaddeyi oluşturduğu ve oransal dağılımlarında ise, obsidiyenin çakmaktaşına göre öncelikli tercih edildiği anlaşılmıştır. Yaygın kullanım gören aletler ise, dilgi, dilgicik, ok ucu, delici, uçlar ve bıçaklardır (Res. 3.1-2). Tepecik’e iki ana bölgeden obsidiyen sağlanmıştır (Kolankaya-Bostancı 2018, s. 146-154, Res. 1-2; Kolankaya-Bostanc1, Carter ve

1 Höyüğün stratigrafik gelişimi için Bkz.: Günel 2010a, s. 25-49; Günel 2014a, s. 83-103, Res. 3, 5-7; Günel 2015a, s. 607-626; Günel 2017a, s. 124-126, Res. 10.3-6; Günel 2018a, s. 538-547, Res. 55.2-6; Günel 2020a, s. 28-39.

2 Çine-Tepecik’te kültür tabakalarına ait farklı cinsteki numunelerin radyokarbon tarihlendirme önerileri, TÜBİTAK, Marmara Araştırma Merkezi Laboratuvarında yapılan analiz örneklerinin neticelerine ve MiamiBETA Laboratuvarının analizlerine dayanmaktadır. 
Weir 2020, s. 85-89). Obsidiyen kaynaklarına ait analiz sonuçları, Ege'de Kiklad adalarından Melos ve Antiparos, Oniki Adalar'dan Giali ile Orta Anadolu'dan Göllü Dağ, Nenezi ve Acı Göl kaynaklarına işaret etmektedir (Kolankaya-Bostancı, Carter ve Weir 2020, s. 8586). Tepecik, her iki bölge ile olan bu iletişimini başlangıçta değiş-tokuş sistemine dayalı gerçekleştirmiş olmalıdır. Alet teknolojisinde, Batı Anadolu Bölgesi'nden tanınan geleneksel yongalama tekniği uygulanmıştır (Kolankaya-Bostancı, Carter ve Weir 2020, s. 87). Höyükte obsidiyen üretim artıklarının ele geçmesi ise, çekirdek halinde temin edilen obsidiyenin yongalama işlemini yerel toplum tarafindan yapıldığına işaret etmektedir (KolankayaBostanc1 2018, s. 147).

Hammaddeye yönelik aktif yürütülen endüstriyel faaliyetlerin yanı sıra seramik sanatı, sosyal ve ekonomik anlamda gelişmiş bir yerel kültürün en belirleyici dinamikleri arasında yer alır. Tepecik'te yaşayan toplumlar, yerel ve aynı zamanda Ege dünyasıyla bağlantılara ip ucu oluşturan seramik geleneğinde ustaların becerilerini öne çıkaran kaplar üretmiştir (Günel 2014a, s. 89; Günel 2018a, s. 540, Fig. 55. 2-6; Günel 2010a, s. 30-44; Günel 2017b, s. 440-455). Tasvir sanatına yönelik bu geleneği, yerleşim sürecinin her döneminde bezeli kap geleneğine verilen öncelik, motif zenginliği ve figüratif kap eklentileri ile anlamak mümkündür (Günel 2007, s. 234-235, Res. 1-2; Günel 2014a, s. 87, Pl. 2A-B, Pl. 2, 5A; Günel 2010b, s. 466, Res.7; Günel 2018b, s. 157, Abb. 2). Ayrıca tasvir sanatına ait figürinler ve kült eşyaları, belli bir düzeye ulaşmış sosyo-kültürel yaşama sşık tutmaktadır (Günel 2008, s. 252-255, Şek. 1-1-5; Günel 2010a, s. 29-39, Fig. 7-24; Günel 2011a, s. 8-16, Abb. 3-5; Günel 2014a, s. 91-93, Pl. 6-10; Günel 2018a, s. 542- 546, Fig. 55. 9-10; Günel 2019a, s. 151-153, Res. 1-7; Günel 2019b, s. 191-193; Günel 2020b, s. 163-168, Res. 2-7).

Kültür tabakalarına yönelik bu genel tanımlama ışığında, Çine-Tepecik’te, en erken kültür tabakasından itibaren kronolojik gelişim içinde boyutları genişleyen bir yerleşim planı görülmektedir. Höyükte Kalkolitik döneme ait kültür tabakası (IV), tarıma dayalı üretim ve hayvan yetiştiriciliğine odaklanmış bir yaşamın izlerini taşımaktadır. Bu kültür tabakası, Batı Anadolu'nun tarım ve hayvan kaynaklarının öncelikli olduğu beslenme gelenekleriyle benzerdir. Ürünlerin depolandığı ambar niteliği taşıyan silolar, farklı boyutlarda öğütme taşları, günlük kullanıma ait çömlekler tarıma öncelik veren bir üretime ve ayrıca koyun, keçi ve sığır gibi hayvan kemiklerinin yoğunluğu ise, besin kaynaklarındaki önceliğe işaret etmektedir (Günel 2006, s. 22, Çiz. 4, Res. 1). Hayvan türleri arasında görülen, geyik, ala geyik ve karacaya ait kemikler ise, bölge faunasının anlaşılmasında ilginç sonuçları ortaya koymuştur. Öte yandan seramik üretimi, pişmiş toprak ve mermer figürinler, mermer kaplar ve takı sanatı, dönemin endüstriyel aktivitelerini belirlemektedir (Res. 4). Seramik geleneği ve tasvir sanatına ait buluntular, Ege kronolojisinde Geç ve Son Neolitik kültürleriyle paralellik göstermektedir (Günel 2014a, s. 87-93, Lev. 1-11; Günel 2018a, s. 540-546, Res. 55.2-55.10). Erken Tunç Çağı kültür tabakası (III) ise, geç dönem kültür tabakaları nedeniyle sınırlı bir 
alanda tespit edilmesine karşın, mimari gelişimini bir yapı örneğiyle yansıtmaktadır. Yapının temeli, iri boyutlarda ve düzgün-beyaz taşlardan oluşmaktadır (Res. 2; Res. 5). Taş temelin üst seviyelerinde, duvarların her iki uzun kenarında iri taşlar iç kısmında ise, daha ufak boyutta taşlar yerleştirilmiştir. Yapının duvar örgü tekniğinde ufak dere taşların oluşturduğu dolgu, taş temel üzerini kaplamaktadır. Ayrıca yapının ara duvar uzantılarında, iri boyutta dere taşları kullanılmıştır. Duvar tekniğine ait bu özellikler, yapıya özgü bir malzemeteknik uygulamanın olduğunu göstermektedir. Duvar kalınlığ Erken Tunç Çağı kültür tabakasına ait bu yapı, duvar tekniği ve boyutları açısından özel bir konuma sahip olmalıdır (Günel 2013, s. 380, Res. 5; Günel 2014a, s. 84-87, Fig. 3-4; Günel 2014b, s. 113). Yerleşmede normal bir yapı duvarına göre belirgin bir kalınlığa sahip olması, söz konusu bu yapıyı farklı kılan faktörler arasındadır. Yapının boyutları ise, 12x6.50 m ölçülerinde düzgün dikdörtgen bir plan oluşturmaktadır.

Yapı içinde doğu duvarına dayanan ve çevresinde günlük kullanıma ait çömlek parçalarının olduğu bir ocak yer almaktadır. Yapının oldukça şiddetli bir yangına maruz kaldığı, kalın bir tabaka oluşturan yanmış kerpiçlerden ve kömürleşmiş ağaç kalıntılarından anlaşılmıştır. Yapı içinde kömürleşmiş ağaç kalıntıları, yuvarlak bir görünüm oluşturmakta ve destek yerlerinin izlerini taşımaktadır. Yapı bu özellikleriyle, Batı Anadolu’nun Erken Tunç Çağı mimari geleneğine uygun, içinde ocakların da yer aldığı dikdörtgen planı vermektedir. Ege dünyasında MÖ 3. Binyıl, sosyal statüyü öne çıkaran yerleşim modellerinin görüldüğü ve genel olarak kamusal yapının merkezi bir konumda yer aldığ 1 bir dönemdir (Erkanal-Şahoğlu 2019, s. 222-225, Çiz. 1; Kouka 2002). Tepecik’te III. kültür tabakasına ait bu yapı, Erken Tunç Çağı'nın sosyo-kültürel gelişimine paralel bir mimari geleneği yansıtmaktadır. Bu kültür tabakasına ait seramik buluntuları arasında kulplu fincan ve depas, dönemin karakteristik kap tipleridir (Podzuweit 1979, s. 9, 151-153, Taf. 6: I-II) (Res. 6.1-2). Seramik ve ayrica tasvir sanatına ait pişmiş toprak ve mermer idoller ve dokuma endüstrisi buluntularından dolgu bezek (inkruste) tekniğinde ağırşaklar kronolojik ayrımda önemli bir rol oynamakta ve bölgelerarası kültürel yakınlığı göstermektedir (Günel 2008, s. 74, Res. 4-5; Günel 2013, s. 380-381, Res. 6-8). Öte yandan bebek bireylerin gömüldüğü çömlek mezarlar ve yetişkin bireylerin gömüldüğü pithos mezarlar, dönemin ölü gömme geleneğine ait mezar tiplerini ve buluntularını vermektedir (Günel 2014b, s. 114-116, Res. 6-7).

Höyükte en erken yerleşim sürecinden itibaren toplumların yaşam biçimi ve geliştirdikleri teknoloji, MÖ 2. Binyılına tarihlenen kültür tabakalarının şekillenmesinde (II 1-2) önemli bir rol oynamıştır. MÖ 2. Binyıl, kentleşme sürecinin mimari ve küçük buluntularıyla çok daha iyi anlaşılmasını sağlamaktadır (Res. 2). MÖ 2. Binyılın kronolojik gelişimine göre, Orta Tunç Çağı kültür tabakası (II 2), bölgesel mimari geleneğinden tanınan yapı taşların kullanıldığı ve yaklaşık duvar kalınlığı 0.40-0.45 m olan malzeme-teknik özellikleri göstermektedir. Bu kültür tabakası, seramik ve taş endüstrisi gibi üretim faaliyetleri ve din anlayışına 1şık tutan 
kült eşyalarıyla dönemin geleneklerini yansıtmaktadır. Seramik üretiminde tasvir sanatına verilen özeni, riton tipinde bir kaba ait geyik başında görmek mümkündür (Res. 7.1-2). Baş, boyun ve kısmen korunmuş boynuzlarda bant bezemeden oluşan mikalı bir süslemenin tüm kaba uygulandığı anlaşılmaktadır. Böylece hayvan biçimli kap ve aynı zamanda mikanın parlak görünüm veren bezeme stiliyle, kaba çok daha görkemli bir görünüm kazandırılmıştır. Seramik sanatında kapların yüzey işlenişinde bol mikalı astar bilinen bir uygulamadır. $\mathrm{Bu}$ yüzey işlenişi, söz konusu geyik başında bantlardan oluşan bir süsleme stiliyle verilmiştir. $\mathrm{Bu}$ bezemenin yanı sıra göz boşluklarının olasılıkla değerli bir taşla kakma olarak işlenmesi de bu eseri ayrıcalıklı kılan diğer bir detaydır. Tasvir sanatına verilen özen, antropomorfik pithosda da görülmektedir. Pithosun boyun kısmında yüz detayları, kulak ve gövdesinde ise, kol ve elin tasvir edilmesi ve ayrıca takılarıyla bir kadın tasviri, bu eseri özgün kılmaktadır (Günel 2015b, s. 213, Abb. 16.1-2). Batı Anadolu Orta Tunç Çağı'na tarihlenen antropomorfik kaplarda, Erken Tunç Çağı'ndan tanınan sadece yüz işlenişine sahip örnekler bilinmektedir (Podzuweit 1979, s. 193, Taf. 15: I-II, Taf. 30: B; Aykurt 2013, Fig. 9; Günel 1999b, s. 5354, Abb. 15, Taf. 12: 4-6; Şahoğlu 2007, s. 316, Fig. 6). Tepecik örneği, Batı Anadolu'nun antropomorfik kap repertuvarında, bir pithos üzerinde takılarıyle birlikte tüm inceliklerin gösterilmeye çalışıldığı bir sanat anlayışının ürünüdür. Bu anlamda bölgenin antropomorfik kaplarından farkındalığını ortaya koymaktadır. Aynı dönemin tasvir sanatında pişmiş toprak bir model ise, stilize boğa başlarından oluşan bir kült eşyasıdır (Günel 2011a, s. 8-11, Abb. 3-5). Model, boğa idollerinin yer aldığı bir sahneyi içermekte ve bölgenin dini inançlarında 'boğa kültüne’ 1şık tutmaktadır (Günel 2020b, s. 164, Res. 2). Bu eserde, boynuzlar çok daha belirgin, gövde ise, şematik işlenmiş olup arka arkaya yerleştirilmiş pozisyonlarıyla derinlik anlayışı verilmeye çalışılmıştır. Modelin form ve boğa idollerine ait boynuz ve gövde işlenişi açısından benzer örnekleri, Kıbrıs'ta mezarlardan ele geçen kült eşyalarıdır (Karş.: Kotchati: Äström 1988, s. 5- 6, Fig. 1-2; Karageorghis 1970, s. 10-12, Pl. I-IV; Karageorghis 1971, s. 344, Fig. 16, 18; Karageorghis 1991, s. 142-143, P1. CII. 2-3, CIII. 1-2, Kalopsidha: Äström 1966, s. 15, Fig. 5; Karageorghis 1970, s. 12, Pl. V; Karageorghis 1991, s. 143, Pl. CIII: 3-4 ve Vounous: Dikaios 1932, s. 346, Pl. LXX-LXXI; Dikaios 1938, s. 1-168, P1. VII-VIII; Karageorghis 1991, s. 139-40, Pl. C: 1-2, CI: 1-2; Peltenburg 1994, s. 159-160, Fig. 1; Voskos ve Knapp 2008, s. 667-668, Fig. 5). Bu eserler, boğa idolleriyle yüceltilmiş dini bir yapının ifade biçimi olmalıdır (Günel 2011a, s. 11-14, Abb. 6-9). Tepecik modeli, 'boğa kültünün' tasvir sanatına bir yansımasının yanı sıra Kıbrıs modelleriyle olan yakınlığıyla bölgelerarası ikonografik birlikteliği göstermiştir. Tepecik'te ocak tabanını sınırlayan ve farklı boyutta olan pişmiş toprak boynuz modeller ise, Anadolu ve Ege'de Minos kültürünün kült eşyalarıyla benzerlik göstermekte ve boğanın din anlayışındaki güçlü konumunu desteklemektedir.

Toplumların kült değerleriyle ilgili geleneklerine 1 şı tutan taş ya da pişmiş toprak boynuz modeller, Neolitik dönemden itibaren geniş bir bölgede takip edilmektedir (Günel 2020b, s. 164-166, Res. 3). Boğa; Anadolu, Mezopotamya, Doğu Akdeniz ve Ege’yi 
kapsayan coğrafyada, adak eşyalarında, duvar resimlerinde, tanrıyı sembolize eden boynuzlu başlık tasvirleriyle anlam kazanmış olup, toplumların dini inançlarında her dönem yerini almıştır (Günel 2020b, s. 163-168). Tepecik’te pişmiş toprak boynuzlar ve boğa idollerinin işlendiği model, Önasya ikonografisiyle benzer tasvir ve kronolojiyi veren kült eşyaları olup, bölgelerarası kült olgusundaki birlikteliğin anlaşılmasını sağlamıştır. Ayrıca söz konusu kült eşyaları, belli bir sosyo-kültürel düzeye ulaşmış toplumlarda öngörülen sanat eserleri olarak değerlendirildiğinde, Tepecik'in bulunduğu bölge için taşıdığı anlam çok daha belirginleşmektedir. Bunu yerleşmeye ait diğer buluntular da destekler niteliktedir.

Orta Tunç Çağı yerleşmesinin endüstriyel faaliyetlerinde yer alan obsidiyen, çakmaktaş1 ve dağ kristalinden aletlerin yanı sıra hammadde kullanımının farklı bir üretimine işaret eden obsidiyen ve dağ kristali kap parçaları, oldukça zarif işlenmiş kaplara aittir. ${ }^{3}$ MÖ 2. Binyılda obsidiyen ve dağ kristalini prestij ürünlerde kullanma geleneği, Anadolu, Ege ve Doğu Akdeniz'i kapsayan coğrafyada, krali ya da elit kesim için üretilen değerli eserler olarak, bölgelerarası kültürel iletişimi ve etkileşimi öne çıkarmıştır (Bevan 2003, s. 57-70; Bevan 2004, s. 111, 115-117, Fig. 6: 3 a-b; Bevan 2007, s. 211; Carter ve Campbell 2000, s. 137; Carter, Campbell ve Gauld 2003, s. 130, Fig. 18; Carter, Contreras, Campeau ve Freund 2016, s. 7, 23, Fig. 4; Carter ve Kilikoğlu 2007, s. 116, Fig. 1; Sowada 2009, s. 149, 152, Fig. 33:189). Tepecik’te lüks eşyalar olarak özel bir anlam taşıyan obsidiyen ve dağ kristali kaplara ait buluntular, söz konusu bu geniş coğrafyada güçlü bir merkez konumunu da belirleyen prestij ürünleridir. Orta Tunç Çağı yerleşmesinde farklı kullanımlara yönelik bu eserler, sosyo-kültürel anlamda belli bir düzeye ulaşmış bir toplumu tanımlayan kanıtlardır.

Çine-Tepecik’te bu gelişim sürecini, Geç Tunç Çağı kültür tabakasında (II 1), savunma sistemine sahip bir yerleşim modeli takip etmektedir (Res. 2). Tepecik’te sur, yer yer 'kiklopik' tarzda iri taşların da kullanıldığg ve taş temel üzerinde kerpiç blokların yükseldiği güçlü duvar yapısına sahiptir (Res. 8). Surda düzenli aralıklarla kare planlı kulelerin yer aldığı savunma sistemi, güçlendirilmiş bir yerleşim planı açısından da belirleyicidir. Sur planı ve kulelerin düzeni, Hitit savunma sistemiyle yakınlık kurulabilecek mimari detayları ortaya koymaktadır (Maner 2019, s. 207, 69). Surla çevrili yerleşmede yer alan yapılardan depo birimleri ve buluntuları, kentin ekonomisinde, üretim faaliyetlerine ve buna yönelik endüstriyel faaliyetlerine ilişkin kanıtları vermiştir. Yerleşmenin kuzey ve batısında depo, atölye/işlik aktivitelerin yürütüldüğü yapılar birbirine yakın bir konumdadır. Tahıl üretimine ait ürünlerin yer aldığı depolama alanları ve pithosların konumları, ekonomik kaynaklarla ilgili bir organizasyona gidildiğini ve farklı depo birimlerinde ürünlerin muhafaza edildiğini ortaya koymuştur (Günel 2011b, s. 70, Res. 2-6; Günel 2018c, s. 103-104, Res. 3-5). Depo birimlerine ait pithoslarda arpa ve buğday öncelikli olmak üzere farklı tahıl ürünleri

3 Obsidiyen kaplarla ilgili yayın, 'Günel, S., Obsidian and Rock Crystal Artefacts as Prestige Finds Based on Raw Material Resources in Çine-Tepecik’ başlı̆̆ı altında hazırlanmaktadır. 
depolanmıştır. Tahıl depolanmış bu pithoslara ait arkeobotanik incelemelerden arpanın buğdaya göre ilk sırada yer aldığı anlaşılmaktadır. ${ }^{4}$ Tepecik tahıl tanelerinin radyokarbon analiz sonuçları, MÖ 1415-1125 tarihlerini kapsayan en az iki yapı evresine sahip bir zaman dilimini vermiştir. ${ }^{5}$

Bu alanda yer alan Resmi Depo'da, pithoslarla bir arada bulunan Anadolu hiyeroglif yazılı mühür baskıları, tahıl ürünlerinin korunduğu pithos ağızlarının mühürlenmesine ilişkin kanıtlardır ve yapıya resmi anlam kazandırmaktadır (Res. 8-9.1-2). Batı Anadolu'da ilk kez bir yapı içinde pithoslarla bir arada ele geçen bu mühür baskıları, Hitit İmparatorluk dönemine tarihlenmektedir (Herbordt içinde: Günel ve Herbordt 2010; Günel ve Herbordt 2014). Mühürlerden birinde, 'Tarkaşnaya' ya da 'Tarkaşnapiya' adının okunması, Arzawa/ Mira ülkesinin kralı 'Tarkaşnawa' ile bağlantı kurulması açısından önemli bir filolojik kaynaktır (Herbordt içinde: Günel ve Herbordt 2010, s. 6, Abb. 4-6). Batı Anadolu'da Menderes ve güneyinin tarihi coğrafyasına 1şık tutan arkeolojik ve filolojik veriler, Arzawa/ Mira topraklarının güney yönündeki yayılım alanına ilişkin önemli kanıtları ortaya koymuştur (Herbordt içinde: Günel ve Herbordt 2010, s. 7-8; Hawkins 1998, s. 26, Abb. 10; Meriç 2020, s. 163-164, Abb. 11). Bu bağlamda, söz konusu mühür baskısı, Çine-Tepecik'in Arzawa/Mira topraklarının güneyindeki konumunu güçlendirmektedir.

Resmi Depo'da ele geçen diğer mühür baskısında ise, bir figür ile hiyeroglif görülmektedir. Mührün ortasında yer alan figür, duruşu, el ve kolların pozisyonu, başlığı ve giysisi ve omuzda taşıdığı yayıyla birlikte tüm detay işlenişiyle, Hitit tasvir sanatından bilinen tanrı betimlemelerinin özelliklerini barındırmaktadır. Figürün önünde yer alan hiyeroglif işaretler 'prens', arkasında yer alan işaretler ise, 'tamipiya' olarak okunmuştur (Herbordt içinde: Günel ve Herbordt 2014, s. 9-11, Abb. 8-10). Mühürler, ikonografik ve filolojik anlamda Hitit krallığının Çine-Tepecik kenti ile bağlantılarını resmi düzeye taşıyan belgelerdir. Bunun yanı sıra Hitit mühür baskılarının Boğazköy-Nişantepe arşivine ait mühürlerle olan benzerliği, Hititlerin Çine-Tepecik kentiyle doğrudan bağlantısını güçlendirmekte ve Hititlerin bölgeyle ilişkilerine 1şık tutmaktadır (Herbordt içinde: Günel ve Herbordt 2010, s. 6).

Arkeolojik anlamda pithos ağızlarının mühürlenerek ürünlerin muhafaza edilmesine yönelik uygulamanın yanı sıra filolojik verileriyle bölgenin tarihi coğrafyasına 1 şık tutan bu mühür baskıları, Resmi Depo yapısının kentin yöneticisine bağlı bir ekonomik sistemin işlediğine yönelik somut kanıtlardır. Depolama birimleri arasında iri boyutlarda pithosların yer aldığ 1 taş platform ise, çok daha geniş çapta ürün depolama işlevine yönelik

4 Arkeobotanik incelemelere ait veriler, kazı ekibinde yer alan İngiltere - Oxford Üniversitesi'nde Tom Maltas'ın ön raporu kapsamında sunulmuştur.

5 Geç Tunç Çağı yerleşmesinde yanmış buğday kalıntılarına ait C14 sonuçları Miami-Beta Laboratuvarının verdiği sonuçlar ve hayvan kemikleri üzerine C14 analiz çalışmaları ise, TÜBİTAK - Maramara Araştırma Merkezi’nin öngördüğü tarihlendirmeler, seramik buluntularıyla benzer bir kronolojiyi vermiştir. 
kullanılmıştır. $\mathrm{Bu}$ alan, pithos gövdelerinin yarıya kadar gömüldüğü ve etrafı ufak taş dolgu ile kaplanarak platform oluşturduğu bir depolama sistemini ortaya koymaktadır. Pithos içlerinde farklı tahıl ürünlerinin tespit edilmesi, aynı pithosda zaman zaman farklı cinslerde ürünlerin depolandığına ve pithosların süreklilik gösteren bir kullanımına işaret etmiştir. Yerleşim planında, yakın alanlarda konumlandırılmış ve birbiriyle bağlantısı olan bu depolama birimleri, kentin ekonomisine ve ticari faaliyetlerine hizmet veren merkezi bir alanı oluşturmaktadır.

$\mathrm{Bu}$ birimlere yakın, sura dayalı depo ile kulelerden birinde bulunan kaplar ise, ticarete yönelik uygulamalarda kulelerin de aktif olarak kullanıldığını göstermiştir. Gerek sura dayanan depoda gerekse kule içinde kapların bir arada ve iç içe istiflenmiş durumda yerleştirilmiş olmaları, malların kente giriş ya da çıkışlarında ve dağıtım aşamasında bu yapıların kullanıldığını göstermektedir. Farklı boyutlarda üretilmiş tabaklar, ithal ve yerli Miken kapları, ticarete dayalı bu dağıtımda yer almıştır. Özellikle surla bağlantılı depoda ve kulede iç içe yerleştirilmiş sığ tabaklar, Resmi Depo yapısına ait sı̆̆ tabaklar, kentin ticari faaliyetlerinde öncelikli mallar arasında olmalıdır (Res. 10). Buna göre, ekonomiye yönelik resmi boyutta her türlü faaliyetin yerleşimde belli bir alanda odaklandığı birimler tesis edilmiştir (Günel 2011b, s. 71, Res. 7; Günel 2013, s. 379, Res. 4). Bu düzenleme ise, yerleşmede kullanım alanlarına göre belli bir planlamanın uygulandığı bir kent modeline işaret etmektedir. Yerleşmenin güney yönünde daha çok hanelerin / yaşam alanlarının varlığını gösteren kanıtlar, bu planlamayı destekler niteliktedir.

Yerleşmede sosyo-ekonomik düzeyin daha iyi anlaşılmasında, hiç şüphesiz seramik, dokuma, yontmataş ve metal endüstrisi olmak üzere çeşitlilik gösteren buluntular önemli bir rol oynamaktadır. Seramik üretiminde malzeme-teknik ve kap formu açısından, Batı Anadolu yerel seramik geleneğinden bilinen kap formları görülmektedir (Res. 11). Günlük kullanıma ait kaplar arasında, fincan, kase ve çömlekler, Orta Tunç Çağı'ndan itibaren en yaygın üretilen ve gelişimini Geç Tunç Çağı seramik teknolojisiyle takip edilen bir malzeme grubu yansitmaktadır (Günel 2007, s. 239, Res. 7; Günel 2008, s. 76, Res. 2; Günel 2009, s. 230, Res. 6; Günel 2010a, s. 28, Fig. 6a-b; Günel 2010b, s. 466, Res. 6; Günel 2011b, s. 71, Res. 8; Günel 2012, s. 22, Res. 6; Günel 2014b, s. 112, Res. 3). Bu kaplar, MÖ 2. Biny1l Batı Anadolu yerli seramiğinden iyi bilinen ve kronolojik ayrımı veren buluntulardır (Karş.; Aykurt 2013, s. 41-57, Fig. 1-9; Blegen, Caskey ve Rawson 1953, s. 159-160, Fig. 366: 170, Fig. 371:162, Fig. 365; Günel 1999a, s. 42-49, Lev. 17-18, 36-45, Lev. 93-96, 123-124; Günel 1999b, s. 51-52, Abb. 12: 9; Lloyd ve Mellaart 1955, s. 79-80, Fig. 18; Lloyd ve Mellaart 1965, s. 82, Fig. P.1, Fig. P.2, 118, Fig. P. 24, 128, Fig. P.31).

Yerleşmede yerli seramik üretimin yanı sıra Miken boya bezeli kaplara ait ithal ve yerli üretim kaplar, Ege dünyasıyla kültürel iletişimin ve aynı zamanda ticari ilişkilerin aktif olduğunu ortaya koymuştur (Res. 12-16). Çine-Tepecik'te Miken boya bezemeli kaseler, 
kraterler (Res.13-14) ve üzengi kulplu kaplarda görülen motifler, Miken bezeme stilinin en karakteristik örneklerini yansıtmakta ve parallel bir kronolojiyi ortaya koymaktadır. Bu motifler arasında, iç içe yarım daireler, içi boyalı yarım daireler ya da dışı noktalarla sınırlanmış iç içe çizgilerin oluşturduğu yarım daireler (Res. 14) olmak üzere çeşitlilik gösteren motifler (FM 43), en popüler bezeme tipleri arasındadır (Günel 2007, s. 236-237, Res. 4-5; Günel 2008, s. 75, Res. 1; Günel 2010a, s. 40, Fig. 16-22, Tab. 4). Ayrıca kaselerde uygulanan dalga bezekler (FM 53) ve krater gibi kalın cidarlı derin kaplar üzerinde görülen dama tahtası da (FM 75:34; FM 56:2) Miken boya bezeli seramik geleneğini yansıtmaktadır (Günel 2007, s. 236-237, Res. 5; Günel 2008, s. 75, Res. 1; Günel 2010a, s. 32-40, Fig. 8-23, Tab. 1, 4).

Spiral bezeli bir kaide ve ayrıca hayvan başının eklendiği örnekler, yerleşmede Miken kaplarına ait çeşitliliği göstermektedir (Günel 2007, s. 236-237, Res. 4). Miken seramiği, Ege ve Doğu Akdeniz'i içeren coğrafyada, GH III B2/GH III C evrelerinin kap formları ve bezeme stilleriyle benzer bir kronoloji vermektedir (Günel 2010a, s. 29-39, Fig. 7-24; Günel içinde: Günel ve Herbordt 2014, s. 4-8, Abb. 3-7).

Miken derin kaseler ve kraterler üzerine belli temaların işlendiği figürlü kap geleneği ise, GH III B2 evresinden itibaren Ege ve Doğu Akdeniz'e uzanan bir yayılım göstermektedir (Günel 2017b, s. 443-452, Res. 2-14; Günel içinde: Günel ve Herbordt 2014, s. 4-8, Abb. 3-7). Ege'de, Miken kaplarında kuş, keçi, boğa ve araba sahnelerinin resimsel bir anlatımla işlendiği örneklere GH III B2-C evrelerinde rastlanmaktadır (Mountjoy 1999, s. 35). Tepecik Miken kaplarında kuş tasvirlerinin gövde ve kanat işlenişindeki detaylarda görülen farklılıklar, oldukça zengin bir repertuvar oluşturmaktadır (Res. 15-16). Figürlü kaplarda kuşlar ve balıklar ya friz halinde ya da keçi, at ve geyik gibi hayvanlarla bir arada resmedilmiştir (Crouwel 2006, Fig. 16; Furumark 1941, s. 250-255, FM 7; Güntner 2000, s. 85-127, 261288, Taf. 38-59; Mountjoy 1999, s. 922, Fig. 376; s. 1073, Fig. 438: 267; s. 1106, Fig. 452: 101; Slenczka 1974, s. 73-75, Taf. 25-31, 39; Vlachopoulos 2003, s. 221, Fig. 4: b).

Figürlü kaplar, Ege ve Doğu Akdeniz'e uzanan coğrafyada MÖ 1350-1200/1190 tarihleri arasında bir kronoloji vermektedir (Meiberg 2011, s. 46-69, 83-94, 103-112, 131-144, 162165, Fig. 3.4-7, Fig. 4.2-4.8, Fig. 5.2-5.7, Fig. 6.1-6.9; Meiberg 2018, s. 323-328, Fig. 1-13; Günel 2017b, s. 446-448). Bu gelenek, GH III C erken-orta evrelerinde, Ege dünyasındaki politik değişime paralel olarak bölgesel bezeme stilleriyle gelişimini sürdürmüştür (Vermeule 1964, s. 206-210; Mountjoy 1999, s. 44, 50; Crouwel 2006, s. 15-22; Crouwel 2007, s. $73-$ 82). Doğu Ege adalarında ve Batı Anadolu'da figürlü seramik geleneğini, Geç Hellas III C orta evresine değin takip etmek mümkündür (Mountjoy 1999, s. 50; Crouwel 2007, s. 73-82; Günel 2017b, s. 443-452, Res. 2-14; Günel içinde: Günel-Herbordt 2014, s. 4-8, Abb. 3-7).

Miken seramiğindeki bu çeşitlilik, Ege'de kültürel anlamda aktif olan bir etkileşimi de ifade etmektedir. Kraterlerde silahlarıyla birlikte işlenmiş figürlerin yer aldığı savaş ya da 
hayvanlarla birlikte resmedilmiş bir avcının işlendiği sahneler, Miken figürlü kap geleneğinde öne çıkan temalardır (Crouwel 2006, s. 16, 20). Tepecik Miken kraterlerinde savaş ve av temasının işlendiği ana sahneler benzer stilde işlenmiş bir resimsel anlatımla görülmektedir (Günel içinde: Günel ve Herbordt 2014, s. 4-8, Abb. 3-7) (Res. 12). Bunun yanı sıra derin kase ve kraterlerde kuş, balık, geyik ve keçi ile bitki tasvirleri, farklı stillerde olmak üzere zengin bir grup oluşturmaktadır. Tepecik’te ithal ve yerli Miken kap tipleri ve bezeme stili, GH III B ve GH III C erken-orta evrelerine tarihlenmekte ve en yakın paralellerine Yunanistan ve Doğu Ege adalarında rastlanmaktadır (Günel 2010a, s. 39-42, Tab. 2, 4; Günel 2017b, s. 446-448).

GH III B ve GH III C, Ege dünyasında bölgelerarası hareketliliğin aktif olduğu bir süreçtir ve Tepecik bölgedeki kültürel ve ticari faaliyetlere dayalı bu dinamiklerde etkin ve güçlü bir kent olarak yerini almıştır. Tepecik'in bu faaliyetlerinde hiç şüphesiz toplumların ekonomik kaynakları ve refah düzeyleri, önemli bir faktördür. Yerleşmede tahıl ekonomisinin öncelikli olduğunu ortaya koyan pithosların yer aldığı depolama birimleri, Orta Anadolu ve Ege dünyasıyla benzer bir sistemi yansıtmaktadır (Christakis 1999, s. 1-20; Christakis 2011, s. 243-244, Fig. 1-2; Schachner 2012, s. 34-36, Res. 9-12; Sarpaki vd. 1989, s. 429, Pl. 65b; Shaw ve Shaw 1993, s. 144, Pl. 22a; Süel 1998, s.42, Res. 9-11; Thumm-Doğrayan, Pavúk ve Pieniążek 2019, s. 171-176, Fig. 4-8).

Endüstriyel faaliyetlere yönelik buluntular ise, üretimde farklı zanaat kollarının varlığını ortaya koymuştur. Bunlar arasında metal endüstrisine ait bronz ok ucu, delici ya da takı sanatına ait küpe ve iğneler yer almaktadır. Metal ile ilgili taşınabilir X-1şını floresansı (pXRF) analizleri, en yoğun bronz olmak üzere, kurşunlu bronz, alaşımlanmamış ve arsenikli bakırdan oluşan bir dağılımı vermektedir. Bronz eserlerde kalay oranının yüksek bir değere sahip olması ise, diğer Batı Anadolu Geç Tunç Çağı merkezlerinden farklı bir tablo oluşturmuştur. Bu sonuçlar, Doğu Akdeniz'de batıklarla bağlantının kurulabileceği bir deniz ticaretine işaret etmektedir. ${ }^{6}$ Öte yandan metal kullanımına rağmen yerleşmede obsidiyen ve çakmaktaşı alet üretimi, bu çalışmanın başında da vurgulandığı gibi, Orta ve Geç Tunç Çağı kültür tabakalarında devam etmiş ve endüstriyel faaliyetler arasında güncelliğini korumuştur.

Yerleşmenin dokuma endüstrisine ait zanaat kolunda ise, farklı tiplerde ve ağırlıklara sahip tezgah ağırlıkları ve ağırşaklar, tekstil üretimindeki ana materyali oluşturmaktadır (Günel 2012, s. 24, Res. 7; Günel 2015b, s. 212, Abb. 15). Tekstil ağırlıkları, sadece bulunduğu coğrafyanın değil, genelinde Ege ve Doğu Akdeniz bölgelerinde kullanım gören ve uygulanan bir geleneği yansıtmaktadır (Alberti vd. 2015, s. 282, Fig. 6.10.9-10; Andersson-Strand ve Nosch 2015, s. 145, Fig. 5. 1.1-5.1.5; Bruun-Lundgren, AnderssonStrand ve Hallager 2015, s. 203, Fig. 6.2.10; Guzowska vd 2015, s. 322-323, Fig. 6.13.23b;

6 Çine-Tepecik metallerine ait analiz ve değerlendirmeler, Chicago Üniversitesi, Mansueto Enstitüsü’nden, Dr. Michele Massa tarafindan verilen ön rapora dayanmaktadır. 
Mårtensson, Nosch ve Andersson-Strand 2009, s. 374, Fig. 2; Olofsson, Andersson-Strand, ve Nosch 2015, s. 92-98, Fig. 4.1.23-32; Rahmstorf 2005; Rahmstorf vd. 2015, s. 269, 273, Fig. 6.9.17-18). Tekstil üretimindeki kaynaklara ip ucu oluşturan veriler ise, yerleşimin her döneminde koyun ve keçi gibi hayvan kemiklerinin yoğunluğu hayvan kaynaklarından dokuma alanında da yararlanıldığını ve ayrıca Büyük Menderes ve Çine Çayı’nın geniş sulak arazilerinde günümüzde olduğu gibi, erken dönemlerde pamuk üretiminin de olabileceğini olası kılmaktadır.

\section{Genel Değerlendirme ve Sonuç}

Çine-Tepecik merkezinin doğal yollar üzerindeki konumuyla, batıda kıyı şeridine açılan uzantıları, doğuda ise, Anadolu'nun iç bölgelerine bağlanması, kültürel dinamiklerde belirleyici olmuştur. Bulunduğu coğrafi bölgede Tepecik, yerleşik yaşamın başladığı en erken dönemlerinden itibaren buluntulariyla ve alet teknolojisiyle Anadolu ve genelinde Ege dünyasıyla benzer bir kültürel gelişimi yansıtmaktadır. Bölgelerarası kültürel ve ticari etkinlikleri, her dönem süreklilik gösteren aktif bir iletişimi barındırmıştır. Bu bağlamda seramik geleneğinde kap tipleri ve bezeme stili, tasvir sanatına ait figürinler ve kült eşyaları, endüstriyel faaliyetlerine ait hammadde ve alet tipleri, Ege bölgesinin kronolojik gelişimiyle paralel bir sosyal yaşamı göstermektedir. Alet teknolojisinde, yontmataş endüstrisine ait obsidiyen ve çakmaktaşı, yerleşim sürecinde önemini yitirmeden kullanım gören hammadde kaynaklarıdır. Obsidiyenin Ege adaları ve Orta Anadolu kaynaklarından temin edilmesi ise, en erken ticari ilişkilere 1şık tutmaktadır.

Çine-Tepecik'te endüstriyel faaliyetlere yönelik farklı zanaat kollarını, taş endüstrisi, metal ve dokuma endüstrisi olmak üzere Tunç Çağları sonuna değin takip etmek mümkündür. Tarım ve hayvancılık üretim modeline öncelik veren ekonomik kaynakları, güçlü bir kent konumuna sahip olmasında önemli bir faktördür. Bu kaynaklar, Tepecik’te yaşayan toplumların sosyo-ekonomik işleyişinde öne çıkmış ve refah düzeyine ulaşmasında önemli bir rol oynamıştır. Geç Tunç Çağı'nda kulelerle desteklenmiş savunma sistemine sahip bir merkez olarak, kültürel gelişimini ve etkileşimleri materyal kültürle yansıtan bir yerleşim sürecini ortaya koymaktadır. Kentin ekonomik gücünü, ürünlerin depolandığı iri pithosların kullanımı ve bu pithosların kapatılması aşamasında kullanılan hiyeroglifli Hitit mühür baskıları çok net olarak göstermektedir. Mühür baskılarına ait filolojik veriler, bir taraftan Çine-Tepecik'in Hitit İmparatorluğu döneminde, Hitit devletiyle ilişkilerin resmi boyutta olduğuna işaret ederken, diğer taraftan, Hititlerin bölgedeki varlığına ve tarihi coğrafyasına kaynak oluşturmaktadır. Çine-Tepecik, Ege dünyasıyla yakınlığını ise, zengin bir grup oluşturan Miken seramik geleneğiyle güçlendirmektedir.

Arzawa/Mira ülkesinin güneyinde yer alan konumuyla Çine-Tepecik, bölgelerarası iletişimini geniş bir coğrafyada yürütebilecek sosyo-kültürel düzeye sahip bir merkezdir. 
Çine-Tepecik'in doğal yollar üzerindeki konumu ve bu bağlamda kara ve deniz iletişimini kullanması, bulunduğu coğrafyanın merkezi güçleri arasında yer almasını sağlamıştır.

\footnotetext{
Hakem Değerlendirmesi: Dış bağımsız.

Çıkar Çatışması: Yazar çıkar çatışması bildirmemiştir.

Finansal Destek: Makalenin ana konusu olan Çine-Tepecik kazılarına ait ana destek, Kültür ve Turizm Bakanlığı, Kültür Varlıkları ve Müzeler Genel Müdürlüğü ile Hacettepe Üniversitesi, Bilimsel Araştırma Projeleri Koordinasyon Birimi tarafından sağlanmaktadır. Teşekkür: Çine-Tepecik Höyüğü kazıları, Bakanlar Kurulu Kararı ve Kültür ve Turizm Bakanlığı'nın izinleriyle, Hacettepe Üniversitesi adına gerçekleştirilmektedir. Kazılar, Kültür ve Turizm Bakanlığı, Kültür Varlıkları ve Müzeler Genel Müdürlügü, Hacettepe Üniversitesi, Bilimsel Araştırma Projeleri Koordinasyon Birimi ve Türk Tarih Kurumu tarafından desteklenmektedir. Kazı projesine, Kaltun Madencilik A.Ş. ve Aydın Büyükşehir Belediye Başkanlığı katkı sağlamaktadır.Burada adı geçen tüm kurumlara içtenlikle teșekkür ederim.
}

Peer-review: Externally peer-reviewed.

Conflict of Interest: The author has no conflict of interest to declare.

Grant Support: The main support for the Çine-Tepecik excavations, which is the main subject of the article, is provided by the Ministry of Culture and Tourism, General Directorate of Cultural Heritage and Museums and Hacettepe University Scientific Research Projects Coordination Unit.

Acknowledgment: The excavations of Çine-Tepecik Mound are carried out on behalf of Hacettepe University, with the decision of the Council of Ministers and the permission of the Ministry of Culture and Tourism. The excavations are supported by the Ministry of Culture and Tourism, the General Directorate of Cultural Heritage and Museums, Hacettepe University, Scientific Research Projects Coordination Unit and the Turkish Historical Society. Kaltun Madencilik A.Ş. to the excavation project and Aydın Metropolitan Municipality contributes. I sincerely thank all the institutions mentioned here.

\section{Kaynakça/References}

Alberti, M. E., Aravantinos, V., Fappas, I., Papadaki, A., Rougemont, F., Andersson-Strand, E., Nosch \& M.-L., Cutler, J. (2015). Textile tools from Thebes, mainland Greece. E. Andersson-Strand \& M.-L. Nosch (Ed.) Tools, Textiles and Contexts, Investigating Textile Production in the Aegean and Eastern Mediterranean Bronze Age, (p. 279-292). Oxford: Oxford Books.

Andersson-Strand, E. \& Nosch, M.-L. (2015). Introduction to the CTR database. E. Andersson-Strand \& M.L. Nosch (Ed.) Tools, Textiles and Contexts, Investigating Textile Production in the Aegean and Eastern Mediterranean Bronze Age, (p. 145-151) Oxford: Oxford Books.

Åstrom, P. (1966) Excavations at Kalopsidha and Ayios Iakovos in Cyprus, 1966.

Åstrom, P. (1988). A Cypriot Cult Scene, Journal of Prehistoric Religio. II, 5-11.

Aykurt, A. (2013). An Updated Assessment on Western Anatolian Middle Bronze Age Chronology in Light of Excavations of the Izmir Region. Colloquium Anatolicum XII, 37-77.

Bevan, A. (2003). Reconstruction the role of Egyptian culture in the value regimes of the Bronze Age Aegean: stone vessels and their social contexts. R. Matthews \& C. Roemer (Ed.), Ancient Perspectives on Egypt, (p. 57-73) London: UCL Press.

Bevan, A. (2004). Emerging Civilized Values? The Consumption and Imitation of Egyptian Stone Vessels in EMII-MMI Crete and its Wider Eastern Mediterranean Context. J. C. Barrett \& P. Halstead (Ed.), The Emergence of Civilisation Revisited, Sheffield studies in Aegean Archaeology, 6, (p. 107-126) Oxford: Oxbow Books.

Bevan, A. (2007). Stone vessels and Values in the Bronze Age Mediterranean. Cambridge: Cambridge University Press. 
Blegen, C. W., Caskey, J. L. \& Rawson, M. (1953). Troy III. The Sixth Settlement. Princeton: Princeton University Press.

Bruun-Lundgren, M., Andersson-Strand, E. \& Hallager, B. P. (2015). Textile tolls from Khania, Crete, Greece. E. Andersson-Strand \& M.-L. Nosch (Ed.) Tools, Textiles and Contexts, Investigating Textile Production in the Aegean and Eastern Mediterranean Bronze Age, (p. 197-206) Oxford: Oxford Books.

Carter, E. \& Campbell, S. (2000). Preliminary Report on the 1998 Season of Excavations at Domuztepe. 21. Kazı Sonuçları Toplantısı, Ankara: Kültür Bakanlığı Yayınları, 133-142.

Carter, E., Campbell, S. \& Gauld, S. (2003). Elusive Complexity: New Data from Late Halaf Domuztepe in South Central Turkey. Paléorient 29, 117-133.

Carter, T., Contreras, D. A., Campeau, K. \& Freund, K. (2016). Spherulites and Aspiring Elites: The Identification, Distribution, and Consumption of Giali Obsidian (Dodecanese, Greece). Journal of Mediterranean Archaeology, 29.1, 3-36.

Carter, T. \& Kilikoğlu, V. (2007). From Reactor to Royalty? Aegean and Anatolian Obsidians from Quartier $\mathrm{Mu}$, Malia (Crete). Journal of Mediterranean Archaeology 20.1, 115-143.

Christakis, K. S. (1999). Pithoi and food storage in Neopalatial Crete: A domestic perspective, World Archaeology 31, 1-20.

Christakis, K. S. (2011). Pithoi and economy in LM IB state societies, T. M. Brogan \& E. Hallager (Ed.), LM IB pottery relative chronology and regional differences, (p. 241-253) Athens: The Danish Institute at Athens.

Crouwel, J. H. (2006). Late Mycenaean Pictorial Pottery a Brief Review. E. Rystedt ve B. Wells (Ed.), Pictorial pursuits. Figurative painting on Mycenaean and Geometric pottery (p. 15-22) Stockholm.

Crouwel, J. H. (2007). Pictorial Pottery of LH III C Middle and its Antecedents. S. Deger - Jalkotzy \& M. Zavadil (Ed.), LH III C Chronology and Synchronisms II LH III C Middle (p. 73-88) Wien.

Dikaios, P. (1932). Les Cultes Préhistoriques Dans L'ile de Chypre. Syria 13, 345-354.

Dikaios, P. (1938). The Excavations at Vounous-Bellapais in Cyprus, 1931-2. Archaeologia 88, 1-168.

Erkanal, H. ve Şahoğlu, V. (2019). Liman Tepe (1992-). V. Şahoğlu, M. Şevketoğlu ve Y. H. Erbil (Ed.) Anadolu, Kültürlerin Bağlantısı. Başlangıcından Roma Dönemi Sonuna Kadar Eski Yakın Doğuda Ticaret ve Bölgelerarasl Ilişskiler / Connecting Cultures. Trade and Interconnections in the Ancient Near East from the Beginning until the End of the Roman Period, (s. 219-230) Ankara.

Furumark, A. (1941). The Mycenaean Pottery. Analysis and Classification, Stockholm.

Guzowska, M., Becks, R., Andersson-Strand, E., Cutler, J. \& Nosch, M.-L. (2015). Textile tools from Troia, western Anatolia. E. Andersson-Strand \& M.-L. Nosch (Ed.) Tools, Textiles and Contexts, Investigating Textile Production in the Aegean and Eastern Mediterranean Bronze Age, (p. 309-328) Oxford Books: Oxford.

Günel, S. (1999a). Panaztepe II. M.Ö. 2. Bine Tarihlendirilen Panaztepe Seramiğinin Batı Anadolu ve Ege Arkeolojisindeki Yeri ve Önemi / Die Keramik von Panaztepe und ihre Bedeutung für Westkleinasien und die Ägäis im 2. Jahrtausend, Ankara: Türk Tarih Kurumu Yayını.

Günel, S. (1999b). S. Günel, "Vorbericht über die mittel- und spätbronzezeitliche Keramik vom Liman Tepe" Istanbuler Mitteilungen 49, 1999, 41-82.

Günel, S. (2006). Çine-Tepecik Höyüğü 2004 Yılı Kazıları, 27. Kazı Sonuçları Toplantısı 1, Ankara: Kültür ve Turizm Bakanlığı Yayını, 19-28. 
Günel, S. (2007). Çine-Tepecik Höyüğü 2005 Yılı Kazıları, 28. Kazı Sonuçları Toplantısı 1, Ankara: Kültür ve Turizm Bakanlığı Yayını, 231-246.

Günel, S. (2008). Çine-Tepecik Höyük 2006 Yılı Kazıları, 29. Kazı Sonuçları Toplantısı 1, Ankara: Kültür ve Turizm Bakanlığı Yayını, 73-90.

Günel, S. (2009). Çine-Tepecik 2007 Yı1ı Kazıları, 30. Kazı Sonuçları Toplantısı 1, Ankara: Kültür ve Turizm Bakanlığı Yayını, 227-240.

Günel, S. (2010a). Mycenaean cultural impact on the Çine (Marsyas) plain, southwest Anatolia: the evidence from Çine-Tepecik, Anatolian Studies, 60, 2010, 25-49.

Günel, S. (2010b). 2008 Yılı Çine-Tepecik Kazıları, 31. Kazı Sonuçları Toplantısı 1, Ankara: Kültür ve Turizm Bakanlığı Yayını, 459-473.

Günel, S. (2011a). Ein Terrakotta-Modell aus Çine-Tepecik, Istanbuler Mitteilungen 61, 7-20.

Günel, S. (2011b). Çine-Tepecik 2009 Yılı Kazıları, 32. Kazı Sonuçları Toplantısı 1, Ankara: Kültür ve Turizm Bakanlığı Yayını, 69-80.

Günel, S. (2012). Çine-Tepecik 2010 Yılı Kazıları, 33. Kazı Sonuçları Toplantısı, Ankara: Kültür ve Turizm Bakanlığ1 Yayını, 19-37.

Günel, S. (2013). Çine-Tepecik 2011 Yılı Kazıları, 34. Kazı Sonuçları Toplantısı, Ankara: Kültür ve Turizm Bakanlığı Yayını, 377-386.

Günel, S. (2014a). New Contributions regarding Prehistoric Cultures in Meander Region: Çine-Tepecik, B. Horejs ve M. Mehofer (Ed.), Western Anatolia before Troy. Proto-Urbanisation in the 4th millennium $B C$ ?, (s. 83-103) Wien.

Günel, S. (2014b). Çine-Tepecik 2012 Yılı Kazıları, 35. Kazı Sonuçları Toplantısı, Ankara: Kültür ve Turizm Bakanlığı Yayını, 111-123.

Günel, S. (2015a). Çine-Tepecik: New Contributions on Late Bronze Age Cultures in Western Anatolia. N. Chr. Stampolidis, Ç. Maner \& K. Kopanias (Ed.), NOSTOI. Indigenous Culture, Migration, Integration in the Aegean Islands, Western Anatolia during the Late Bronze Age-Early Iron Age, (p. 607-626) İstanbul: Koç Üniversitesi Yayınları.

Günel, S. (2015b), Ein Zentrum mit interregionalen Beziehungen in Westanatolien in der Bronzezeit: ÇineTepecik/Bronz Çağında Batı Anadolu'da Bölgelerarası Bağlantıları Gösteren Bir Merkez: Çine-Tepecik. Ü. Yalçın \& H. D. Bienert (Ed.), Anatolien-Brücke der Kulturen. Aktuelle Forschungen und Perspektiven in den deutsch-türkischen Altertumswissenschaften, (p. 205-216) Bonn: Grafisches Centrum Cuno GmbH\&Co.KG.

Günel, S. (2017a). The West: Archaeology. M. Weeden ve L. Z. Ullmann (Ed.), Hittite Landscape and Geography, Koninklijke BRILL, (p. 119-133) Leiden/Boston.

Günel, S. (2017b). Çine-Tepecik Yerleşmesine Ait Figürlü Miken Seramiği. E. Kozal, M. Akar, Y. Heffron, Ç. Çilingiroğlu, T. E. Şerifoğlu, C. Çakırlar, S. Ünlüsoy \& E. Jean (Ed.), Questions, Approaches, and Dialogues in Eastern Mediterranean Archaeology, Studies in Honor of Marie-Henriette and Charles Gates, (p. 439-455) Münster: Ugarit-Verlag.

Günel, S. (2018a). The Prehistoric Culture in Çine-Tepecik and Its Contribution to the Archaeology of the Region. S. Dietz, F. Mavridis, Z. Tankosić \& T. Takaoğlu (Ed.), Communities in Transition: The CircumAegean Area During the 5th and 4th Millennia BC, (p. 538-547) Oxford: Oxbow Books.

Günel, S. (2018b). Die Beziehungen der ägäisch-westanatolischen Kulturen im 2. Jt.v. Chr. Ü. Yalçın (Ed.), Anatolian Metal VIII, Eliten-Handwerk-Prestigegüter, (p.157-167) Bochum. 
Günel, S. (2018c). Çine-Tepecik 2016 Yılı Kazıları, 39. Kazı Sonuçları Toplantısı, 1. Ankara: Kültür ve Turizm Bakanlığı Yayını, s. 101-112.

Günel, S. (2019a), Çine-Tepecik Kilia Tipi Figürinleri, F. Kulakoğlu, T. Yıldırım, T. Sipahi, V. Şahoğlu, H. L. Keskin (Ed.), Uğur Silistreli Anı Kitabl: Anadolu Arkeolojisi Üzerine Yazılar / In Memoriam Uğur Silistreli: Studies on Anatolian Archaeology, (p. 149-158).Ankara,

Günel, S. (2019b). Batı Anadolu-Ege İlişkilerinin Çine-Tepecik Merkezine Yansımaları, Anadolu, Kültürlerin Bağlantısı. V. Şahoğlu, M. Şevketoğlu, Y. H. Erbil (Ed.), Başlangıcından Roma Dönemi Sonuna Kadar Eski Yakın Doğuda Ticaret ve Bölgelerarası İlişkiler / Connecting Cultures. Trade and Interconnections in the Ancient Near East from the Beginning until the End of the Roman Period (p.187-204), Ankara.

Günel, S. (2020a). Karia Bölgesi'nin Kentleşme Sürecinde Çine-Tepecik Höyüğü/The Process of Urbanization in Caria in Light of Çine-Tepecik Mound. O. C. Henry \& A. Belgin-Henry (Ed.), Karialılar Denizcilerden Kent Kuruculara / The Carians from Seafarers to City Builders, (p. 28-41) İstanbul: Yap1 Kredi Yayınları.

Günel, S. (2020b). Çine-Tepecik Tasvir Sanatında 'Boğa Kültü' Yansımaları. H. Gönül Yalçın ve O. Stegemeier (Ed.), Metallurgica Anatolica, Festschrift für Ünsal Yalçın anlässlich seines 65. Geburtstag / Ünsal Yalçın 65. Yaşgünü Armağan Kitabı, (s. 163-170) İstanbul: Ege Yayınları.

Günel, S. \& Herbordt, S. (2010). Ein hethitischer Siegelabdruck aus Çine-Tepecik. Archäologischer Anzeiger, 1-11.

Günel, S. \& Herbordt, S. (2014). Mykenische Kraterfragmente mit figürlichen Darstellungen und ein Siegelabdruck eines hethitischen Prinzen aus der spätbronzezeitlichen Siedlung von ÇineTepecik. Archäologischer Anzeiger, 2014/1, 1-14.

Güntner, W. (2000). Figürlich Bemalte Mykenische Keramik aus Tiryns, Tiryns XII. Mainz am Rhein.

Hawkins, J. D. (1998). Tarkasnawa King of Mira ‘Tarkondemos’, Boğazköy Sealings and Karabel. Anatolian Studies 48, 1-31.

Karageorghis, V. (1970). Two Religious Documents of the Early Cypriote Bronze Age, Report of the Department of Antiquities. Cyprus, 10-13.

Karageorghis, V. (1971). Chronique des fouilles et Découvertes Archéologiques À Chypre en 1970. Bulletin de Correspondance Hellénique 95, 335-432.

Karageorghis, V. (1991). The Coroplastic Art of Ancient Cyprus I. Chalcolithic-Late Cypriote I. Nicosia.

Kolankaya-Bostancı, N. (2018). Çine-Tepecik 2016 Yılı Yontmataş Endüstrisi. 33. Arkeometri Sonuçları Toplantısı 2, (s. 145-160) Ankara: Kültür ve Turizm Bakanlığı Yayınları.

Kolankaya-Bostanc1, N., Carter ve Weir, T. E. (2020). Çine-Tepecik Höyük Obsidiyen Tedarik ve Takas Sistemi. Hacettepe Üniversitesi, Edebiyat Fakültesi Dergisi, 37 (1), 83-95.

Kouka, O. (2002). Siedlungsorganization in der Nord-und Ostägäis während der Frühbronzezeit (3. Jt. V.Chr.). Raden Westfalia.

Lloyd, S. \& Mellaart, J. (1955). Beycesultan Excavations: First Preliminary Report. Anatolian Studies 5, 39-92.

Lloyd, S. \& Mellaart, J. (1965). Beycesultan II: Middle Bronze Age Architecture and Pottery. London: The British Institute of Archaeology at Ankara.

Maner, Ç. (2019). "Du sollst für die Ewigkeit bauen!” Untersuchungen zu hethitischen und mykenischen Befestigungen. Bonn: Verlag Dr. Rudolf Habelt GmbH.

Mårtensson, L., Nosch, M.-L. \& Andersson-Strand, E. (2009). Shape of Things: Understanding a Loom Weight. Oxford Journal of Archaeology, 28:4, 373-398. 
Meiberg, L. G. (2011), Figural Motifs on Philistine Pottery and their Connections to the Aegean World, Cyprus and Coastal Anatolia. Ph. D. Dissertation, Pennsylvania: University of Pennsylvania.

Meiberg, L. G. (2018). Decorative Motifs on Philistine Pottery and their Connections to Crete. I. Shai, J. R. Chadwick, L. Hitchcock, A. Dagan, C. McKinny \& J. Uziel (Ed.), Ägypten und altes Testament 90, Tell it in Gath Studies in the History and Archaeology of Israel, (p. 322-335) Münster: Zaphon

Meriç, R. (2020). The Arzawa Lands. The Historical Geography of Izmir and Its Environs during Late Bronze Age in the Light of new Archaeological Research. TÜBA-AR 27, 151- 177.

Mountjoy, P. A. (1999). Regional Mycenean Decorated Pottery. Rahden.

Olofsson, L., Andersson-Strand E. \& Nosch, M.-L. (2015), Experimental testing of Bronze Age textile tools. E. Andersson-Strand \& M.-L. Nosch (Ed.) Tools, Textiles and Contexts, Investigating Textile Production in the Aegean and Eastern Mediterranean Bronze Age, (p. 75-100) Oxford: Oxford Books.

Peltenburg, E. (1994). Constructing Authority: The Vounous Enclosure Model. Opuscula Atheniensia 20 (10), 157-162.

Podzuweit, C. (1979). Trojanische Gefäßformen der Frühbronzezeit in Anatolien, der Ägäis und angrenzenden Gebieten, Mainz am Rhein: Verlag Philipp von Zabern.

Rahmstorf, L. (2005). Ethnicity and changes in weaving technology in Cyprus and the eastern Mediterranean in the $12^{\text {th }}$ century BC. V. Karageorghis, H. Matthäus \& S. Rogge (Ed.), Cyprus: Religion and Society from the Late Bronze Age to the end of the Archaic Period. Proceedings of an International Symposium on Cypriote Archaeology, (p. 143-169) Erlangen.

Rahmstorf, L., Siennicka, M., Andersson-Strand, E., Nosch, M.-L. \& Cutler, J. (2015). Textile tools from Tiryns, mainland Greece. E. Andersson-Strand \& M.-L. Nosch (Ed.) Tools, Textiles and Contexts, Investigating Textile Production in the Aegean and Eastern Mediterranean Bronze Age, (p. 267-278) Oxford: Oxford Books.

Sarpaki, A., Weingarten, J., Macgillivray, J. A., Sackett, L. H., Driessen, J., Bridges, R. \& Smyth, D. (1989). Excavations at Palaikastro, 1988, Annual of the British School at Athens, 84, 417-445.

Schachner, A. (2012). Orta Anadolu'da Coğrafya ve Ekonomi: Hititlerin Bıçak Sırtındaki İmparatorluğu, Colloquium Anatolicum 11, 25-54.

Shaw, J. W. \& Shaw, M. C. (1993). Excavations at Kommos (Crete) during 1986-1992, Hesperia, 62, 129190 .

Slenczka, E. (1974). Figürlich Bemalte Mykenische Keramik aus Tiryns, Tiryns VII. Mainz am Rhein.

Sowada, K. N. (2009). Egypt in the Eastern Mediterranean during the Old Kingdom: An Archaeological Perspective. Switzerland: Academic Press Fribourg.

Süel, A. (1998). Ortaköy-Şapinuwa: Bir Hitit Merkezi, TÜBA-AR 1, 37-61.

Şahoğlu, V. (2007). Çeşme-Bağlararası: A New Excavation in Western Anatolia, F. Felten, W. Gauss \& R. Smetana (Ed.). Middle Helladic Pottery and Synchronisms. (p. 309-322) Vienna.

Thumm-Doğrayan, D., Pavúk, P. \& Pieniążek, M. (2019). Economy and Storage Strategies at Troy, Country in the City. Agricultural Functions in Protohistoric Urban Settlements (Aegean and Western Mediterranean), D. Garcia, R. Orgeolet, M. Pomadère \& J. Zurbach (Ed.), (p. 169-187) Archaeopress Archaeology.

Vermeule, E. (1964). Greece in the Bronze Age. Chicago: The University of Chicago Press.

Vlachopoulos, A. (2003). The Late Helladic III C ,Grotta Phase“ of Naxos. Its Synchronisms in the Aegean and Ist Non-Synchronisms in the Cyclades. S. Deger-Jalkotzy \& M. Zavadil (Ed.). LH III C Chronology 
and Synchronisms. Proceedings of the International Workshop Held at the Austrian Academy of Sciences at Vienna, (p. 217-234) Wien.

Voskos, I. \& Knapp, A. B. (2008). Cyprus at the End of the Late Bronze Age: Crisis and Colonization or Continuity and Hybridization? American Journal of Archaeology, 112, 659-684. 


\section{Şekil, Resim, Tablo ve Grafikler / Figures, Tables and Graphics}

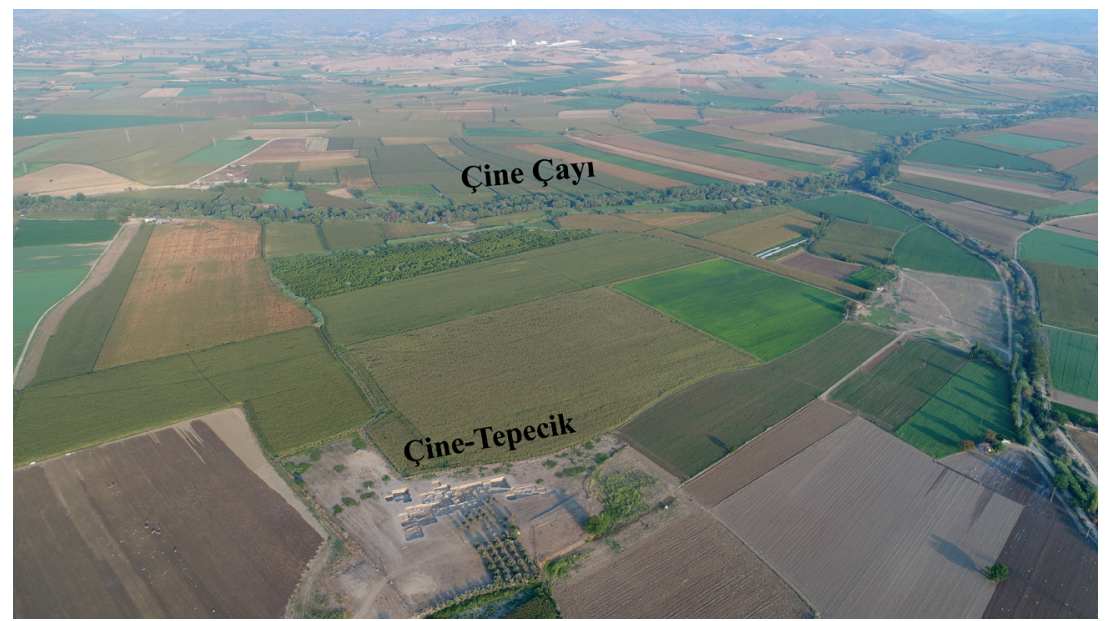

Resim 1. Çine ovası; Çine-Tepecik'in konumu

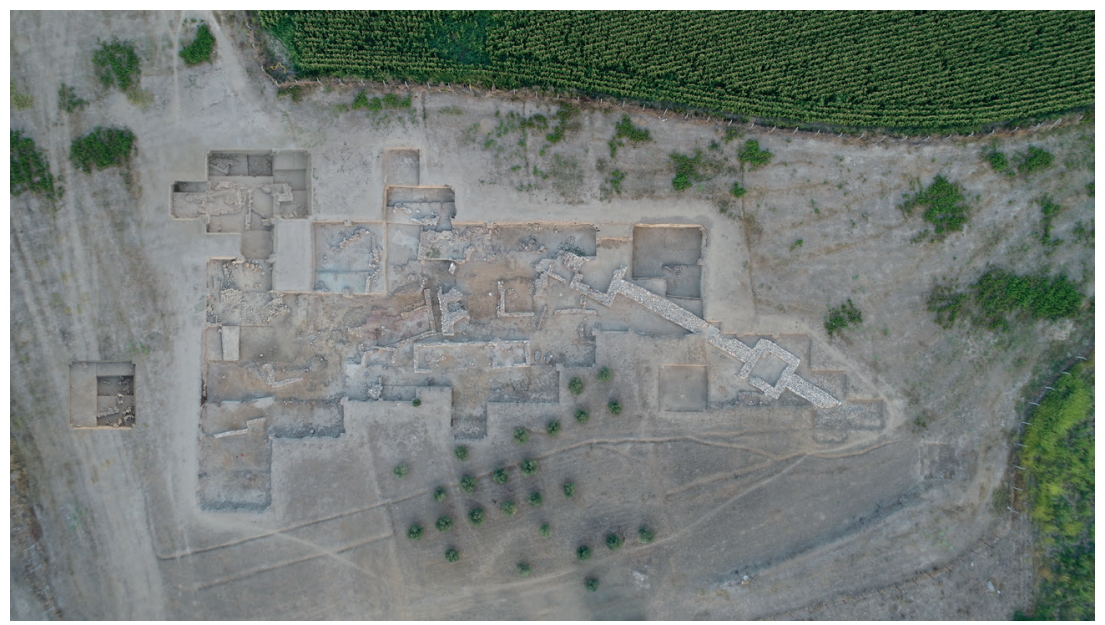

Resim 2. Çine-Tepecik yerleşmesi; genel görünüm 


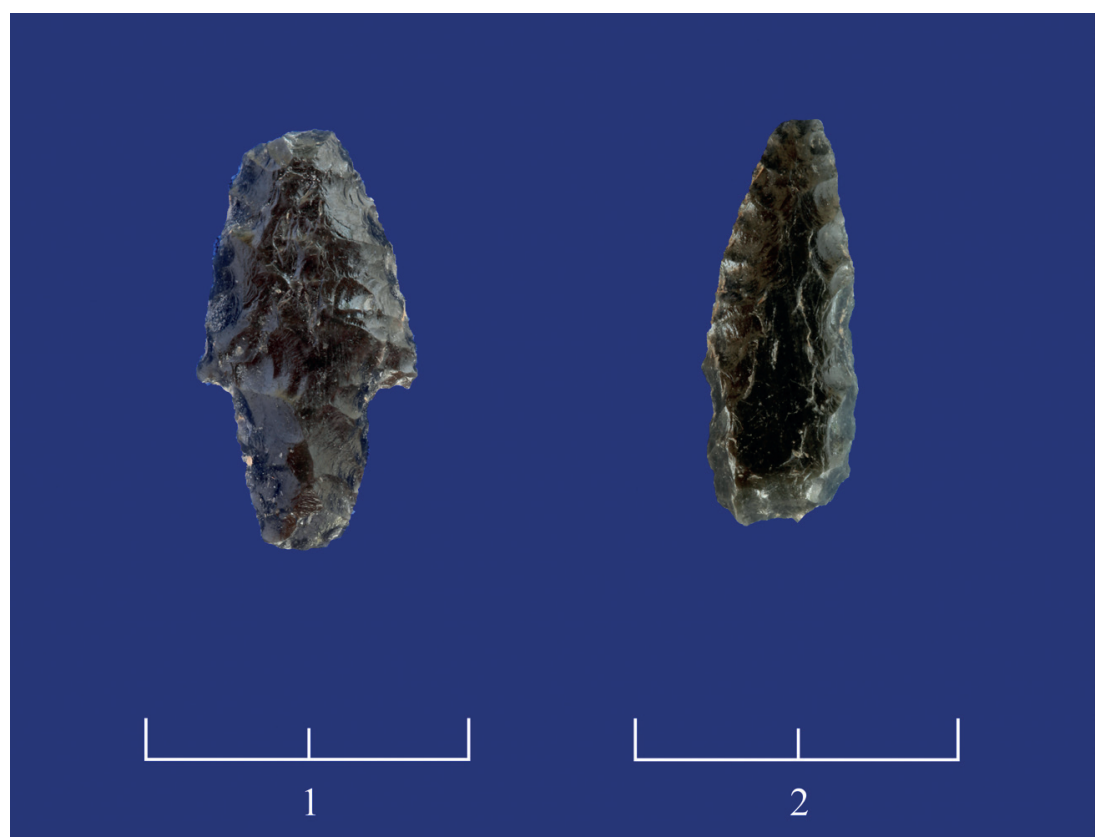

Resim 3. Kalkolitik Çağ; obsidiyen aletler, 'Saliagos' tipi ok ucu

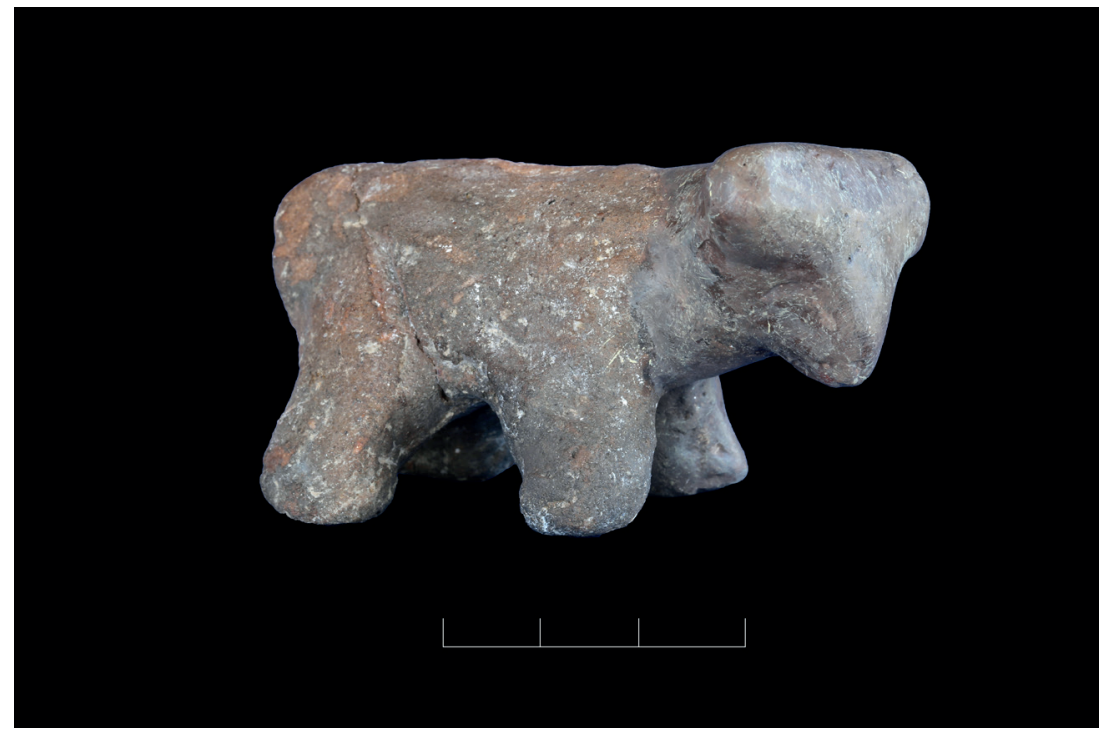

Resim 4. Kalkolitik Çağ; pişmiş toprak figürin 


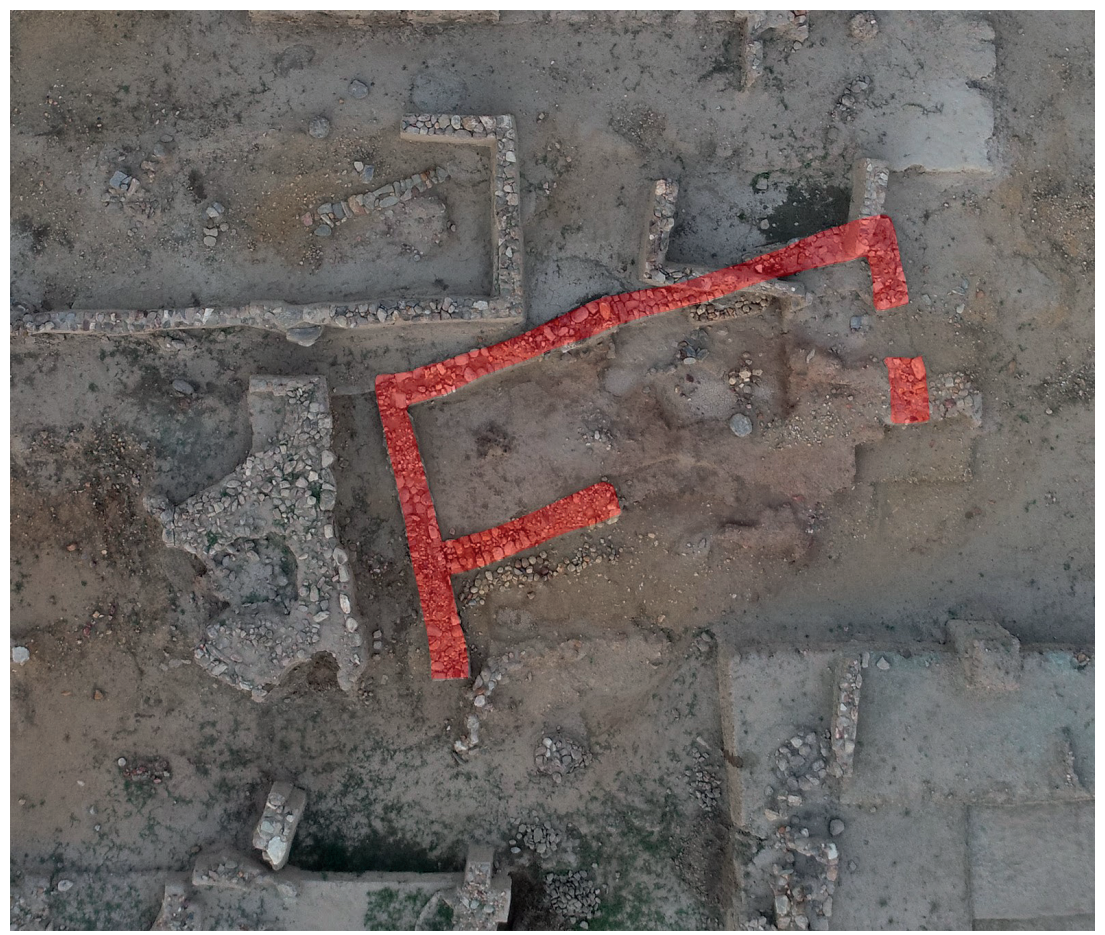

Resim 5. Erken Tunç Çağı; mimari - yapı planı

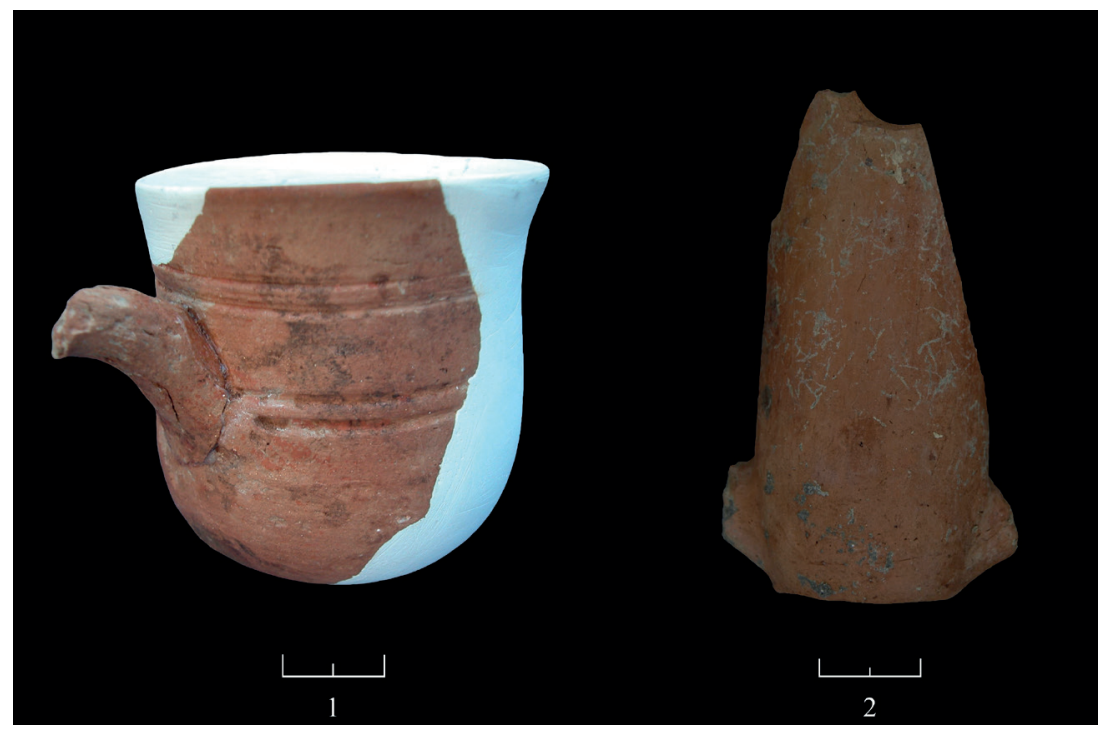

Resim 6. Erken Tunç Çağı; fincan ve depas 


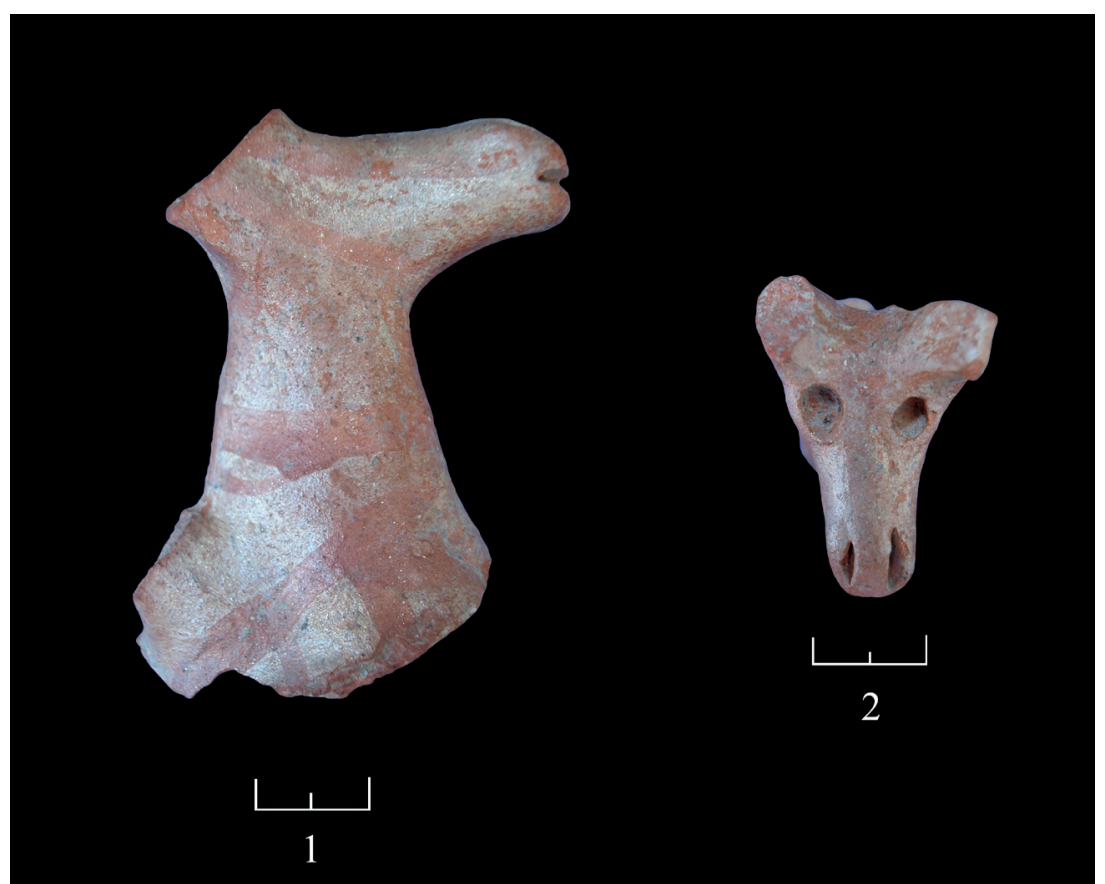

Resim 7. Orta Tunç Çağı; ryton parçası 


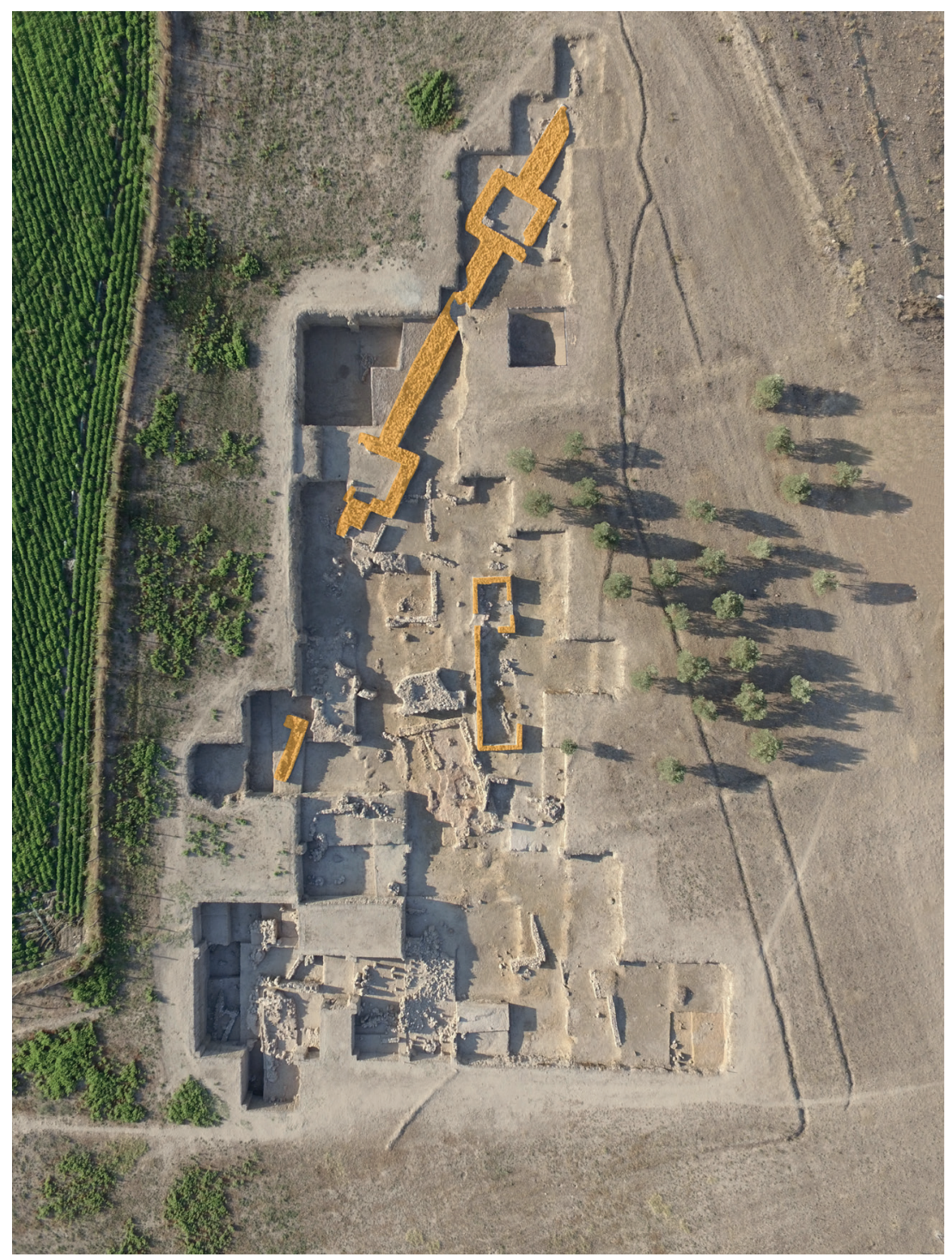

Resim 8. Geç Tunç Çağı; yerleşim planında savunma sistemi ve Resmi Depo 


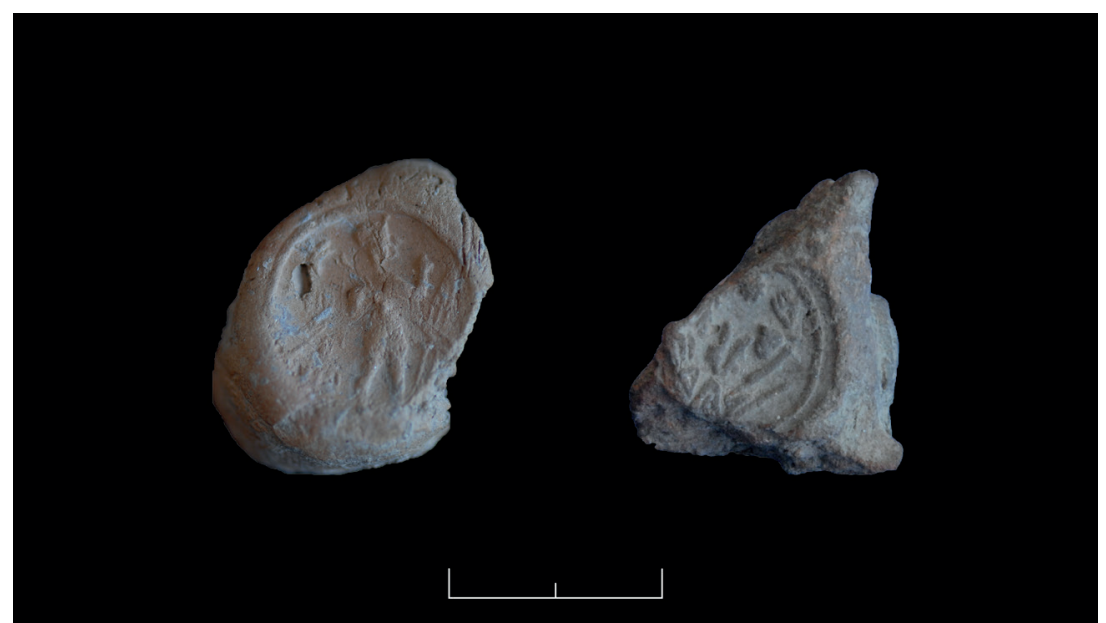

Resim 9. Geç Tunç Çağı; Hitit İmparatorluk dönemi mühür baskıları

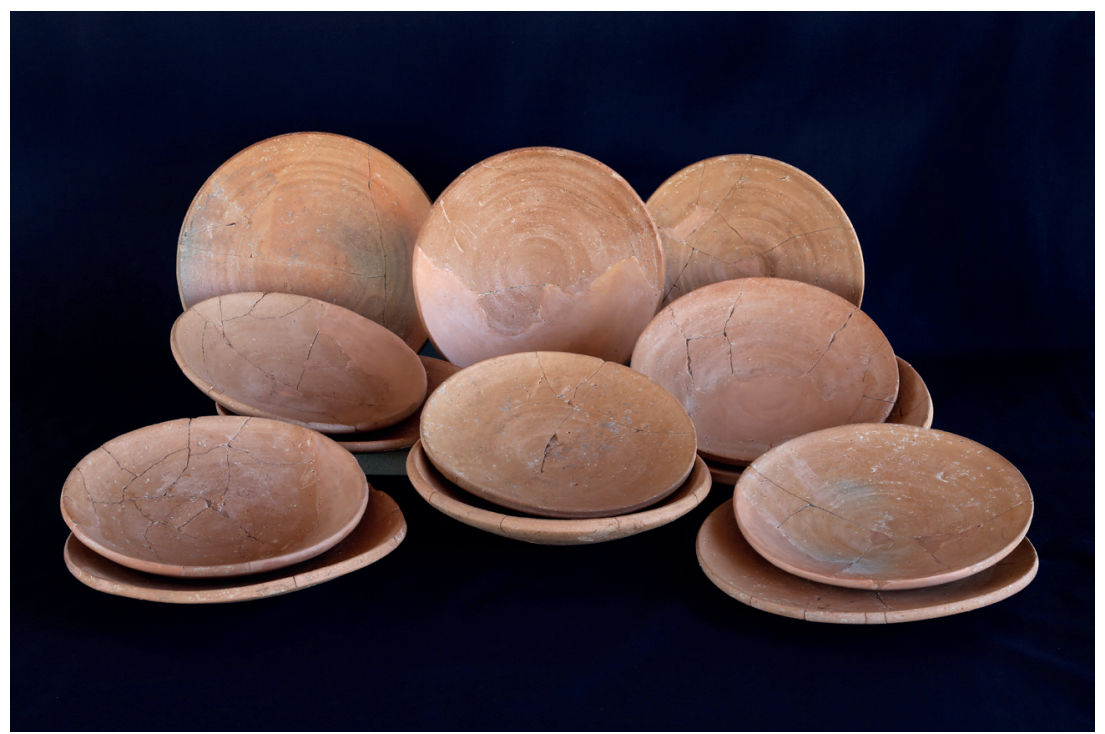

Resim 10. Geç Tunç Çağı; yerli seramik, tabaklar 


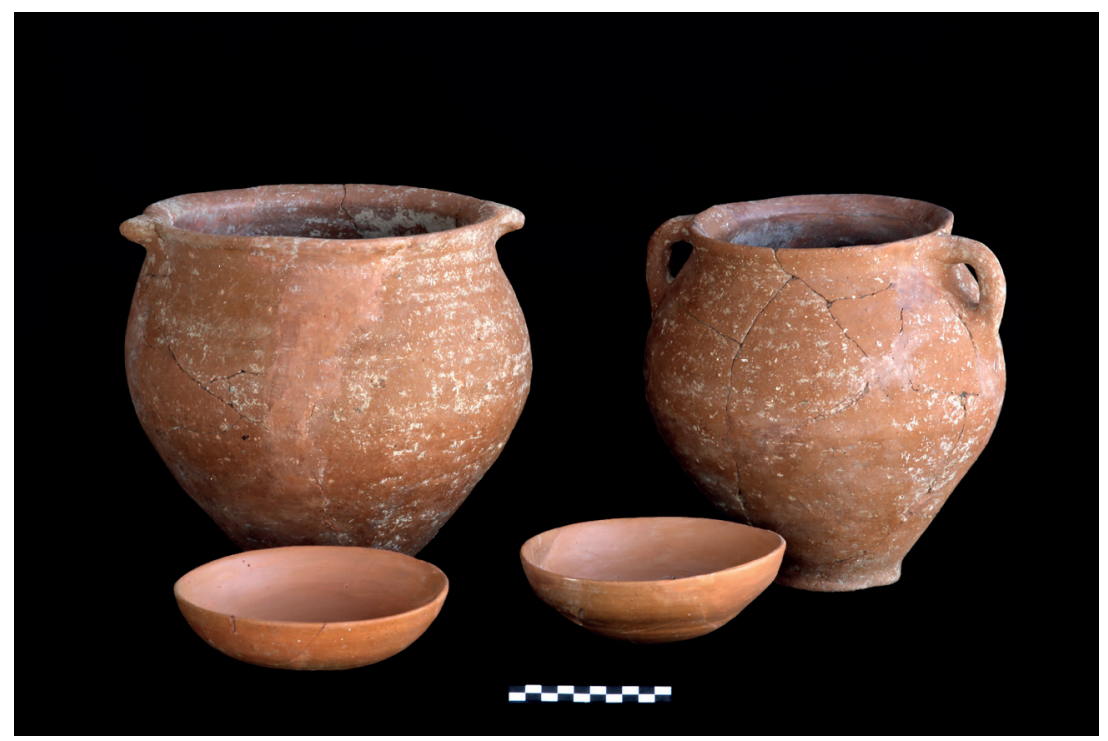

Resim 11. Geç Tunç Çağı; yerli seramik, çanak ve çömlekler

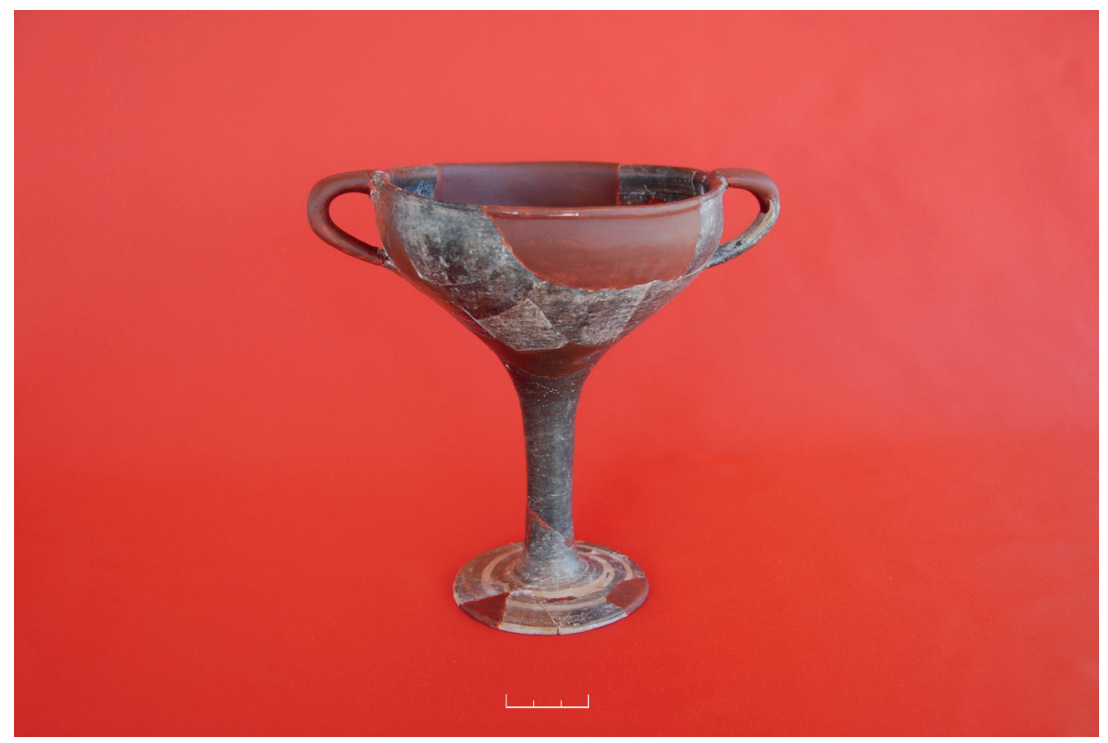

Resim 12. Geç Tunç Çağı; Miken seramiği, Kylix 


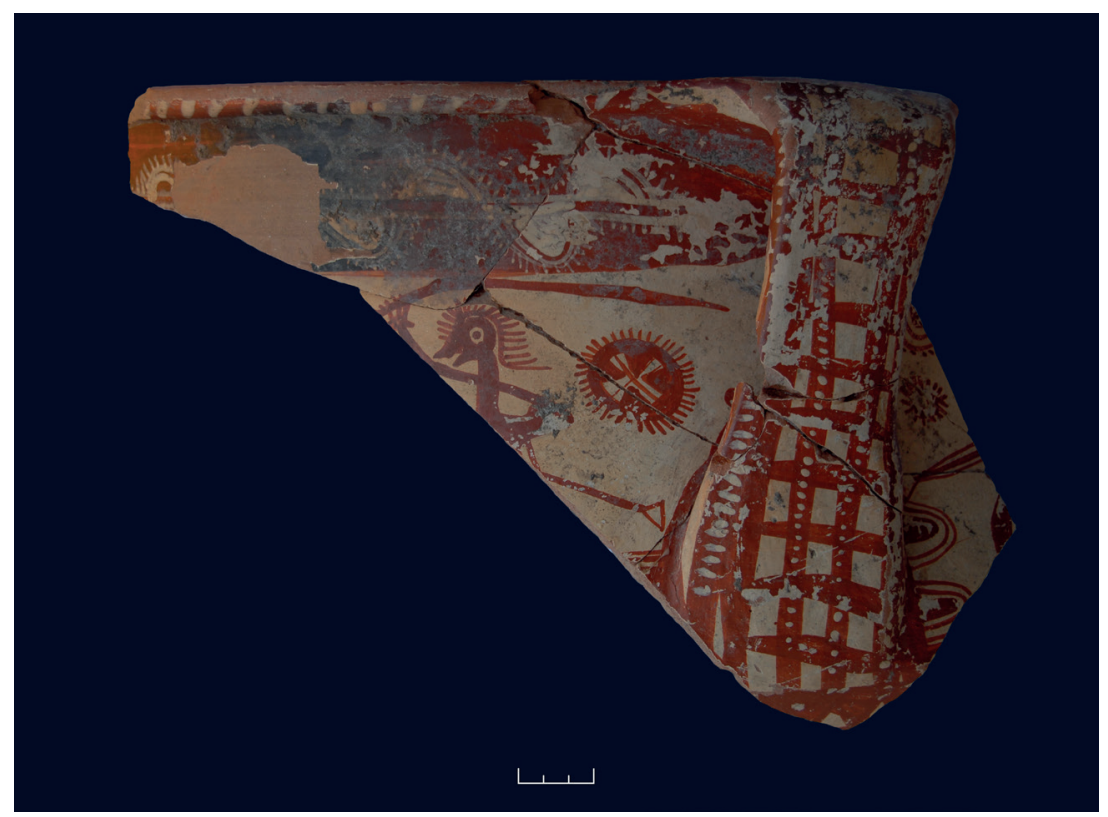

Resim 13. Geç Tunç Çağı; Miken seramiği, Figürlü Krater

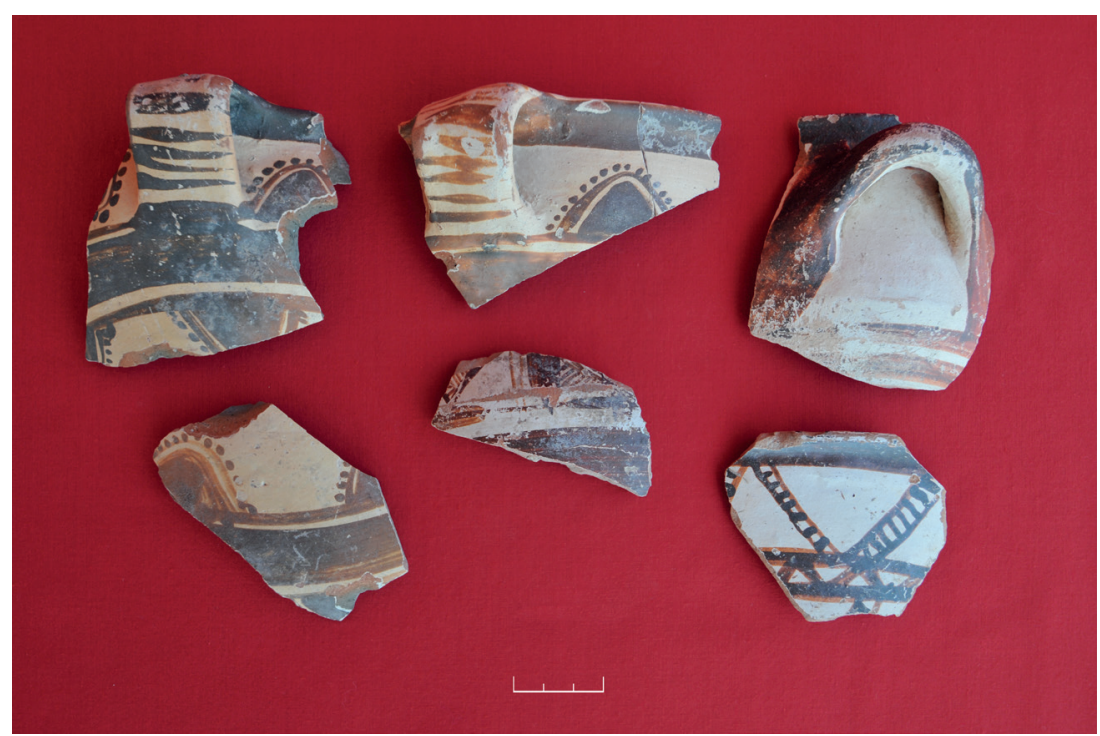

Resim 14. Geç Tunç Çağı; Miken seramiği, kap parçaları 


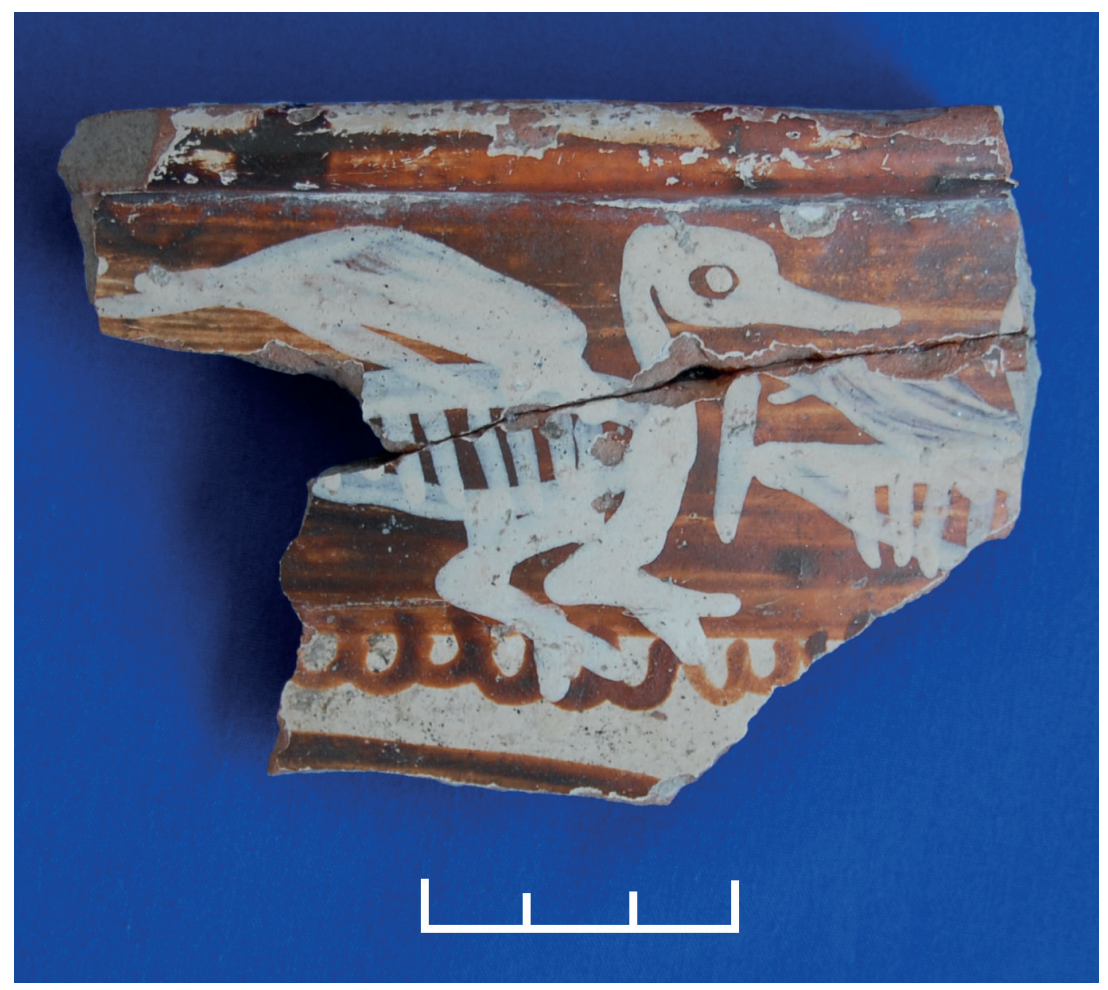

Resim 15. Geç Tunç Çağı; Miken seramiği, Figürlü kap parçası

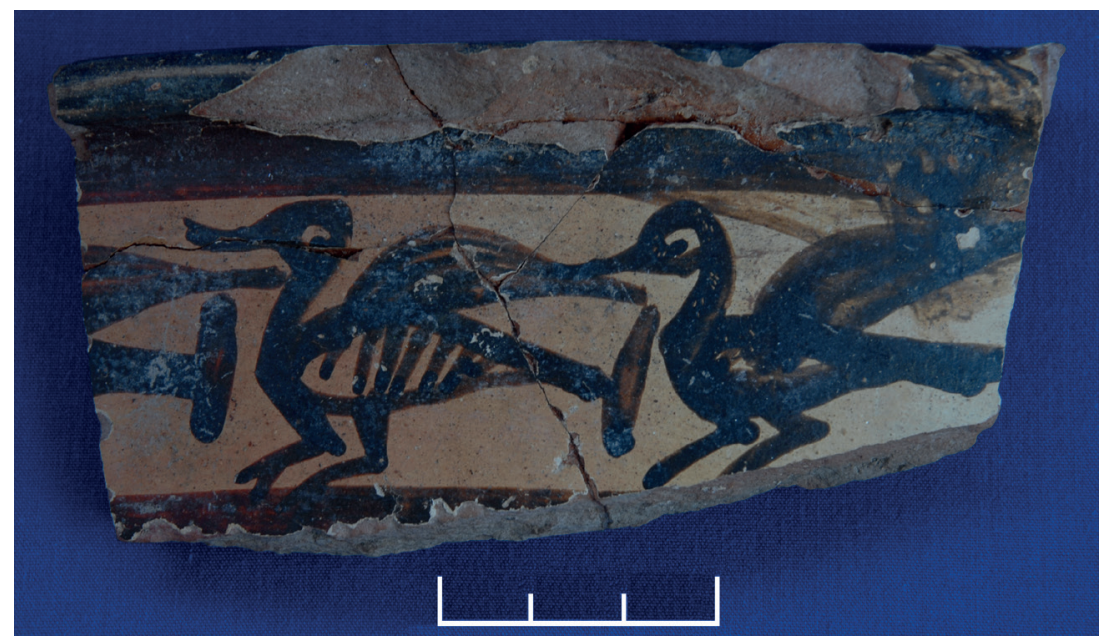

Resim 16. Geç Tunç Çağı; Miken seramiği, Figürlü kap parças1 